\title{
Synthesis, physical, optical, mechanical, and radiation attenuation properties of $\mathrm{TiO}_{2}-\mathrm{Na}_{2} \mathrm{O}-\mathrm{Bi}_{2} \mathrm{O}_{3}-\mathrm{B}_{2} \mathrm{O}_{3}$ glasses
}

\author{
A.S. Abouhaswa a,b, Hesham M.H. Zakaly ${ }^{\mathrm{a}, \mathrm{c}, * *}$, Shams A.M. Issa ${ }^{\mathrm{c}, \mathrm{d}}$, M. Rashad ${ }^{\mathrm{d}, \mathrm{e}}$, \\ Maria Pyshkina $^{\mathrm{a}, \mathrm{f}}$, H.O. Tekin ${ }^{\text {,** }}$, R. El-Mallawany ${ }^{\mathrm{b}}$, Mostafa Y.A. Mostafa ${ }^{\mathrm{a}, \mathrm{h}}$ \\ ${ }^{a}$ Ural Federal University, Yekaterinburg, 620002, Russia \\ ${ }^{\mathrm{b}}$ Physics Department, Menoufia University, Shebin El Koom, 32511, Egypt \\ ${ }^{c}$ Physics Department, Faculty of Science, Al-Azhar University, 71524, Assuit, Egypt \\ ${ }^{\mathrm{d}}$ Physics Department, Faculty of Science, University of Tabuk, Tabuk, Saudi Arabia \\ ${ }^{\mathrm{e}}$ Physics Department, Faculty of Science, Assiut University, Assiut, 71516, Egypt \\ ${ }^{\mathrm{f}}$ Institute of Industrial Ecology UB RAS, Ekaterinburg, Russia \\ ${ }^{\mathrm{g}}$ Medical Diagnostic Imaging Department, College of Health Sciences, University of Sharjah, Sharjah, 27272, United Arab Emirates \\ ${ }^{\mathrm{h}}$ Minia University, Faculty of Science, Department of Physics, El-Minia, Egypt
}

\section{A R T I C L E I N F O}

\section{Keywords:}

Bismuth-borate glass

Shielding properties

FLUKA

Mechanical

UVA

\begin{abstract}
A B S T R A C T
A series of bismo-borate $(50-\mathrm{x}) \mathrm{B}_{2} \mathrm{O}_{3}-\mathrm{xTiO}_{2}-15 \mathrm{Na}_{2} \mathrm{O}-30 \mathrm{Bi}_{2} \mathrm{O}_{3}$ glass samples (where $\mathrm{x}=0,2.5,5,7.5$, and $10 \mathrm{wt}$ \%) doped with $\mathrm{TiO}_{2}$ were fabricated via the melt-quenching technique. The gamma and neutron shielding, physical, optical, and mechanical properties of the prepared samples were investigated. The experimental results were measured using an HPGe detector. ${ }^{152} \mathrm{Eu},{ }^{133} \mathrm{Ba},{ }^{137} \mathrm{Cs}$, and ${ }^{60} \mathrm{Co}$ radioactive sources were used with energies in the range of 81-1408 keV. The experimental results were compared with both the FLUKA code and the XCOM database. The addition of $\mathrm{TiO}_{2}$ increased the density of the glass samples and decreased their molar volume. The mass attenuation coefficient (MAC) decreased as photon energy decreased, while it increased as $\mathrm{TiO}_{2}$ concentration increased. The half value layer (HVL) and mean free path (MFP) of the glass samples increased when the photon energy increased and decreased as the TiO2 concentration increased. The absorbance of the present samples is enhanced by using $\mathrm{TiO}_{2}$, meaning they can be used to protect humans from UV light. Both direct and indirect band gaps decreased as $\mathrm{TiO}_{2}$ content increased from 0 to 10 wt \%. Moreover, the electronic transition between localized states is valid in the present samples. The radiation shielding, optical, physical, and mechanical properties of the fabricated glass samples demonstrate their utility for diagnostic gamma shielding.
\end{abstract}

\section{Introduction}

The term of natural radiation comprises such as radiation from the cosmic region and the radiation arising from the decay of natural radionuclides. The primordial radioactive elements of the Earth crust, their radioactive products and the radiation nuclides produced by cosmic radiation interactions are included in the natural radionuclides. These are present in the Earth's crust. On the other hand, it is also emitted by man-made radioactive sources, which are utilized in many fields of activity like cultivation, manufacturing, nuclear power, and medical researches [1]. After recognizing that radioactive sources are harmful to humans, scientists began to protect themselves against radiation, particularly higher energy gamma radiation and permeation.
Principally, thick shielding materials should be utilized in areas that contain radioactive resources or waste in order to maintain the initial amount of radiation as-low-as possible. Among the traditional shields, Lead $(\mathrm{Pb})$ is one of the most frequently utilized protective material because of its different characteristic advantages such as high atomic number, material density. In addition, $\mathrm{Pb}$ is known for its availability in different structural forms such as powder and glass [2]. In addition to the remarkable benefits of $\mathrm{Pb}$ such as softness and rigidity, on the other hand, it has some disadvantages such as massive weight, toxic structure and production of secondary radiation. Radiation shielding plays a substantial role in the evolution of high-performance radiation facilities, especially for mobile equipment and consolidated systems like wagon-mounted neutron sources, naval nuclear propulsion on systems,

\footnotetext{
* Corresponding author. Medical Diagnostic Imaging Department, College of Health Sciences, University of Sharjah, Sharjah, 27272, United Arab Emirates.

** Corresponding author. Ural Federal University, Yekaterinburg, 620002, Russia.

E-mail addresses: h.m.zakaly@azhar.edu.eg (H.M.H. Zakaly), tekin765@gmail.com (H.O. Tekin).
} 
space reactors, and other advanced nuclear systems [3-5]. The fundamental objective of radiation shielding design is to create a shield surrounding the nuclear radiation facilities to reduce the radiation dose as much as possible [6]. As nuclear facilities have limited space available, the shield should be consolidated, lightweight, and specialized [7]. The physical properties of materials depend strongly on their chemical composition, density, and bonding forces [8]. Due to a low price and ease of fabrication, concrete materials are widely used in gamma radiation shielding. Unfortunately, concrete materials develop cracks over time due to tensile stress, thus becoming ineffective. Moreover, concrete materials are opaque [9] Thus, glass materials could be a useful alternative for radiation shielding. Glass materials with high chemical durability, high transparency, and grand radiation shielding properties are essential in many applications. Glass materials containing lead $(\mathrm{Pb})$ are used extensively in radiation shielding applications due to their super absorbance of gamma radiation [10]. However, as $\mathrm{Pb}$ is toxic to the environment and human beings, it should be replaced by $\mathrm{Pb}$-free glass materials [11]. $\mathrm{B}_{2} \mathrm{O}$-based glasses have unique characteristics like high transmittance and thermal stability, resulting in interesting materials for use in various applications like glass ceramics, mechanical sensors, and radiation shielding [12]. In addition to large IR transmission window, their high refractive-index makes $\mathrm{Bi}_{2} \mathrm{O}_{3}$ glasses an ideal optical component. When $\mathrm{Bi}_{2} \mathrm{O}_{3}$ is used as a modifier, it takes up both Network formation and Network Modification positions because due to its highest valance. The addition of Bi to borate glasses as heavy metal ions improves the radiation shielding properties. The addition of transition metals like titanium dioxide to glass produces a material useful in various applications. In two-oxidation states $\mathrm{Ti}^{3+}$ and/or $\mathrm{Ti}^{4+}$ ), titanium ions can participate in a glass network [13]. Many scientists have been looking for a more adequate attenuator that can protect the living biological tissues and organs from hazardous effects of gamma photons. On the other hand, another issue attributed to this ongoing investigation is to provide some essential advantages such as cost-effectiveness, high durability, non-toxicity, lightweight, and portability [14-17]. By considering the recent investigations and needs for superior shields, this work aimed to perform a large experimental characterization on a different type of $\mathrm{TiO}_{2}$, reinforced glasses in terms of their optical, nuclear radiation shielding and mechanical properties. Accordingly, $\mathrm{xTiO}_{2}-15 \mathrm{Na}_{2} \mathrm{O}-30 \mathrm{Bi}_{2} \mathrm{O}_{3}-(50-\mathrm{x}) \mathrm{B}_{2} \mathrm{O}_{3}$ glass system and manufactured samples (where $\mathrm{x}=0,2.5,5,7.5$ and $10 \mathrm{wt}^{\circ}$ / o) have been investigated. The definition of an ideal radiation shield can be classified with different titles. In addition to attenuation properties, mechanical and optical properties are also of decisive importance in this regard. Therefore, radiation shielding, optical, and mechanical properties of the prepared glass samples have synergistically been investigated. It is worth mentioning that experimental gamma-ray attenuation parameters have been determined using 14 different gamma-ray energies ranging from 81 to $1408 \mathrm{keV}$. The results obtained from this study can make a significant contribution to the glass literature, especially in terms of the development of the novel glassy systems based on similar chemical structure of recent glasses.

\section{Materials and methods}

\subsection{Fabrication of glass samples}

Melt-quenching technique has been used to synthesize samples of the $\mathrm{xTiO}_{2}-15 \mathrm{Na}_{2} \mathrm{O}-30 \mathrm{Bi}_{2} \mathrm{O}_{3}-(50-\mathrm{x}) \mathrm{B}_{2} \mathrm{O}_{3}$ glass (where $\mathrm{x}=0,2.5,5,7.5$ and $10 \mathrm{wt} \%)$. The samples were named:

TNB1: $50 \mathrm{~B}_{2} \mathrm{O}_{3}+35 \mathrm{Bi}_{2} \mathrm{O}_{3}+15 \mathrm{Na}_{2} \mathrm{O}+0 \mathrm{TiO}_{2}$

TNB2: $47.5 \mathrm{~B}_{2} \mathrm{O}_{3}+35 \mathrm{Bi}_{2} \mathrm{O}_{3}+15 \mathrm{Na}_{2} \mathrm{O}+2.5 \mathrm{TiO}_{2}$;

TNB3: $45 \mathrm{~B}_{2} \mathrm{O}_{3}+35 \mathrm{Bi}_{2} \mathrm{O}_{3}+15 \mathrm{Na}_{2} \mathrm{O}+5 \mathrm{TiO}_{2}$;

TNB4: $42.5 \mathrm{~B}_{2} \mathrm{O}_{3}+35 \mathrm{Bi}_{2} \mathrm{O}_{3}+15 \mathrm{Na}_{2} \mathrm{O}+7.5 \mathrm{TiO}_{2}$;

TNB5: $40 \mathrm{~B}_{2} \mathrm{O}_{3}+35 \mathrm{Bi}_{2} \mathrm{O}_{3}+15 \mathrm{Na}_{2} \mathrm{O}+10 \mathrm{TiO}_{2}$.
The operation process and implemented steps for glass fabrication can be listed as follows;

i) Boron oxide $\left(\mathrm{B}_{2} \mathrm{O}_{3}\right) 99.99 \%$, bismuth oxide $\left(\mathrm{Bi}_{2} \mathrm{O}_{3}\right) 99.99 \%$, sodium oxide $\left(\mathrm{Na}_{2} \mathrm{O}\right) 99.99 \%$, and titanium oxide $\left(\mathrm{TiO}_{2}\right)$ 99.999\% were mixed and pre-heated at $300{ }^{\circ} \mathrm{C}$ for $2 \mathrm{~h}$.

ii) The mixtures were molten in porcelain crucibles at a temperature of $1100{ }^{\circ} \mathrm{C}$ for $30-45 \mathrm{~min}$.

iii) Next, they were placed into a stainless mold to give the glass samples a disc shape.

iv) The glass samples were then transferred to a muffled burner at $300{ }^{\circ} \mathrm{C}$ to anneal.

\subsection{Structure and optical measurements}

In this study, material densities and molar volume calculations are calculated by using the well-known Archimedes rule. Next, weights of the fabricated glass-specimens were determined in air and toluene ( $\rho_{\text {liq }}=0.866 \mathrm{~g} / \mathrm{cm}^{3}$ at room temperature) using a 4-digit sensitive microbalance. X-ray diffraction (XRD) investigations were carried out using a Bruker AXS D8 Advance diffractometer (Germany) $\left(\mathrm{Cu}_{\mathrm{K \alpha}}\right.$ radiation) to analyze the structure of the samples at room temperature. To determine the optical properties of fabricated glass samples, JASCO UV-Vis-NIR model V-570 spectrophotometer was utilized on polished glass discs.

\subsection{Gamma attenuation measurements}

The gamma detecting unit BDECi-40 190 is designed to convert Gamma Quanta energy into electrical signals, using a detector made of especially pure germanium. This signal is proportionate to the spectrometric or another piece of nuclear physical equipment in amplitude for subsequent processing. In this study, MSPA 5.03 software and an HPGe-0 I spectrometer were successfully utilized to record Gamma-ray spectra. (see Fig. 1). It is worth mentioning that extensive technical properties of used HPGe spectrometer can be obtained from literature, elsewhere [18]. Exemplary gamma-ray spectrometric sources (OSGI) have been used to calibrate detector registration efficiency, which certified at VNIIM (St. Petersburg). ${ }^{241} \mathrm{Am},{ }^{133} \mathrm{Ba},{ }^{152} \mathrm{Eu}$, and ${ }^{137} \mathrm{Cs}$ radionuclides were used to calibrate the spectrometer [19]. The gamma-ray attenuation coefficients of the investigated glass samples were obtained for 12 energy lines (121.8, 244.7, 344.3,444, 778.9, 867.4, 964.1, 1112.1 and $1408 \mathrm{keV}),(81$ and $356 \mathrm{keV}),(1173$ and $1332 \mathrm{keV}$ ) and $662 \mathrm{keV}$ ): these were emitted from ${ }^{152} \mathrm{Eu},{ }^{133} \mathrm{Ba},{ }^{60} \mathrm{Co}$, and ${ }^{137} \mathrm{Cs}$ radioactive sources, respectively. All samples were measured five times in order to reduce the statistical error. The gamma spectra without and with the TNB5 glass sample at $662 \mathrm{keV}$ are shown in Fig. 2.

The mass attenuation coefficients values of the fabricated glasses are described in terms of the measured transmitted photon energy intensity through glass thickness $t$ and incident photon intensity $I_{0}$ according to the Beer-Lambert law:

$I=I_{0} e^{-(L A C / \rho) t}$

where LAC is the linear attenuation coefficient. It is not possible to measure the LAC using the narrow-beam geometry technique. In order to the scattered-radiations, which are always penetrated the detector along with the transmitted beam, the transmitted radiation intensity will be calculated by the modified Lambert-Beer's law:

$B F=\exp \left[\left(L A C_{t h}-L A C_{\text {exp }}\right) t\right]$

Using the weight elements $\left(\mathrm{w}_{\mathrm{i}}\right)$ in glasses, the MAC theoretical values were calculated with the XCOM [20] database:

$M A C=\sum_{i} w_{i}(M A C)_{i}$

The desired glass thickness should reduce the absorbed radiation 
intensity to one-half and one-tenth of the initial radiation: these are called the half-value layer (HVL) and tenth-value layer (TVL), respectively, and are acquired using the following equations [21]:

$H V L=\frac{\ln (2)}{L A C}$

$T V L=\frac{\ln (10)}{L A C}$

Glass with a thickness of one mean free path (MFP) absorbs 0.36 .8 of the initial gamma intensity when it passes through the glass. It is calculated by Ref. [22]:

$M F P=\frac{1}{L A C}$

Three more substantial parameters are the transmission factor (TF) (the ratio of the radiation intensity crossing through the glass to the incident intensity on the surface of the glass), $\mathrm{Pb}$-equivalent thickness $\left(\mathrm{d}_{\mathrm{Pb}}\right)$, and radiation protection efficiency (RPE). They are given by eqs [23].:

$T F(\%)=\frac{I}{I_{0}} \times 100$

$\operatorname{RPE}(\%)=\left(1-\frac{I}{I_{0}}\right) \times 100$

$d_{P b}=\frac{L A C_{\text {glass }}}{L A C_{P b}} \times t_{\text {glass }}$

\subsection{Theoretical and simulation calculations}

Today, scientific studies having their transformation through the novel methods and challenges instead of traditional investigation methods. In particular, radiation studies are found as suitable for radiation transportation simulations based on Monte method. The term of Monte Carlo method is a promising tool due to its solution-oriented estimation process in critical situations. The literature review has shown that several well-known radiation transport cedes based on Monte Carlo method are being used by researchers. Among the frequently used codes, FLUKA is a radiation transport code with its userfriendly properties and extensive physics libraries [24]. On the other hand, simple and complex geometries can be designed through the FLUKA Monte Carlo code [25,26]. A database analysis interface, known as Flair, was used for editing files and code running. The mono-energetic photon source was defined by a BEAM card. A BEAM POS card was used to set the position and direction of the source. The sample was modeled as a rectangular parallelepiped (RPP) with a cross-section of $10 \mathrm{x} 10 \mathrm{~cm}$ and a thickness of $0.4 \mathrm{~cm}$. The modeling of sample materials was done with MATERIAL and COMPOUNDS cards. The MATERIAL card was used to define the selected composition with required information such as density, descriptive material number and elemental fractions. The COMPOUNDS card allows for defining the mixture of different materials with various weight fractions of atoms. The detector volume was placed inside a cylindrical collimator with an outer diameter of $10 \mathrm{~cm}$, an inner diameter of $0.4 \mathrm{~cm}$, and a length of $4 \mathrm{~cm}$ : it was made of lead to prevent scattered radiation. The detector volume is presented as a cylinder with a diameter of $0.4 \mathrm{~cm}$ and a length of $2.3 \mathrm{~cm}$ : all free space was filled with a vacuum to avoid scattered photons. In the detector volume, the number of incoming photons was detected by a USRBIN card. The USRBIN card requires only the type of particles7 and the region of the detector volume. In order to obtain high accuracy, 106 primary particles were run through the simulation (Fig. 3). 


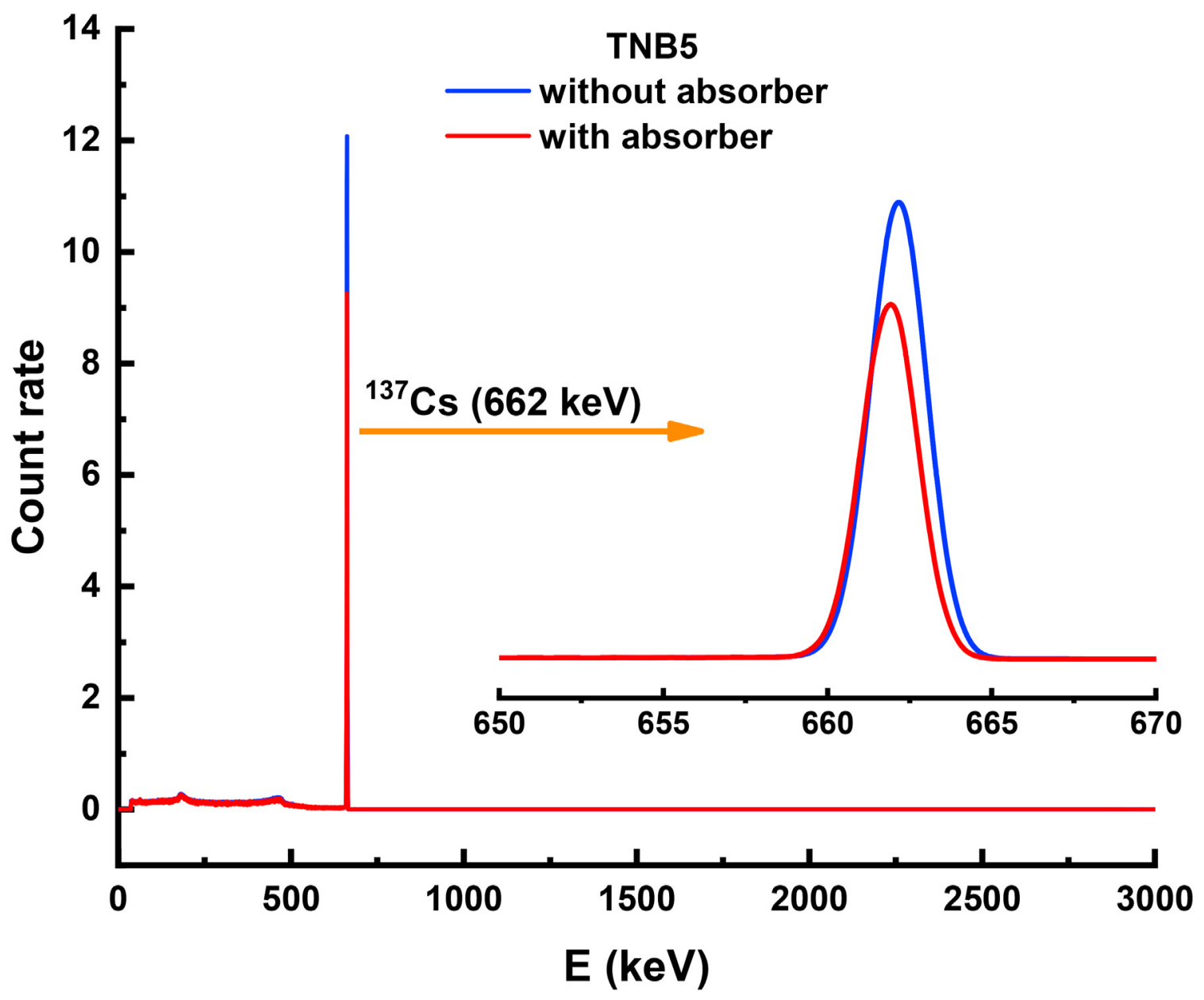

Fig. 2. The gamma spectrum with and without absorber of TNB5 glass sample.

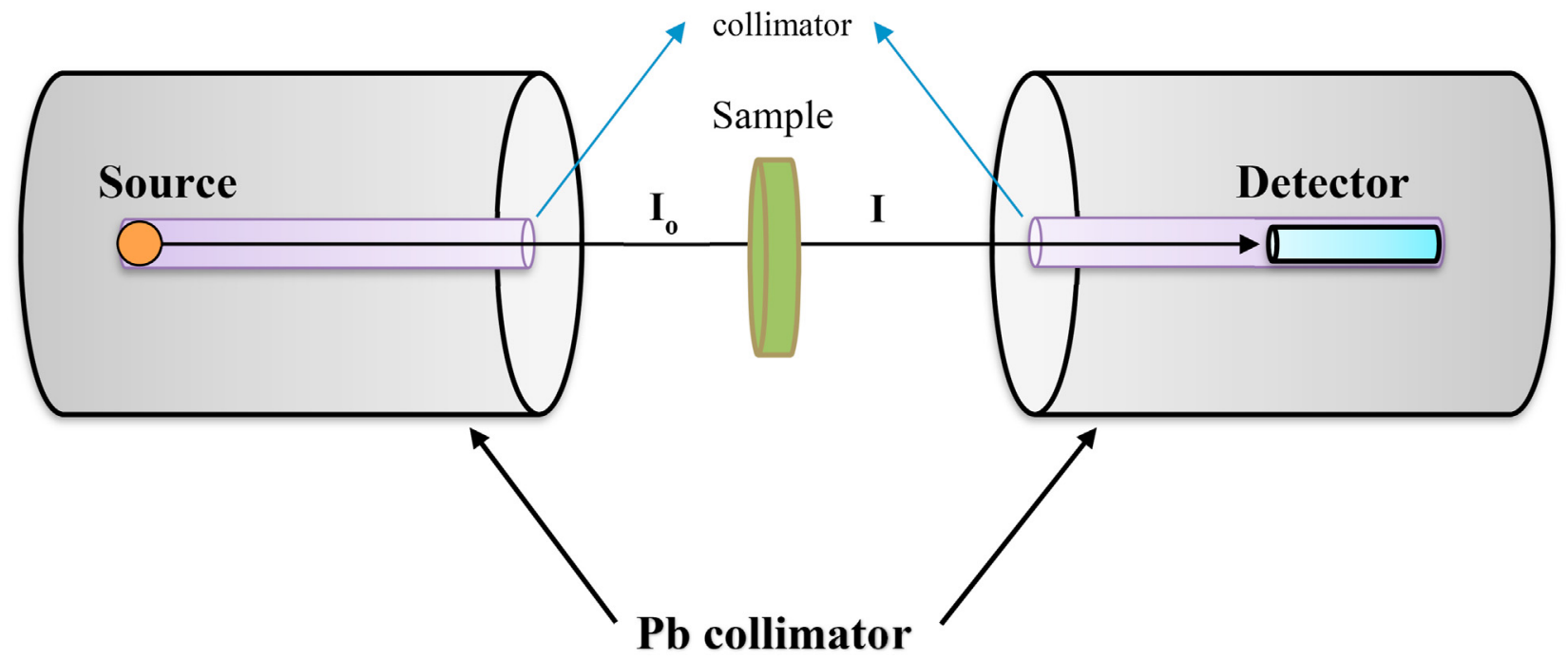

Fig. 3. FLUKA Monte Carlo simulation setup used for mass attenuation coefficients calculations of glasses.

\subsection{Fast neutron removal cross-sections}

The term of effective removal cross-section, $\Sigma_{R}\left(\mathrm{~cm}^{-1}\right)$, explains the potential of a neutron to cross through the glass without interaction. The $\Sigma_{\mathrm{R}}$ of any composite can be predicted using [27]:

$\Sigma_{R}=\sum_{i}\left(\Sigma_{R} / \rho\right)_{i} w_{i}$ where $\left(\Sigma_{\mathrm{R}} / \rho\right)_{\mathrm{i}}$ is the removal cross-section of the ith component.

\subsection{Mechanical properties}

The following parameters such as oxygen volume (MOV), oxygen packing density (OPD), fractal bond connectivity (d), number of bonds per unit volume $\left(\mathrm{n}_{\mathrm{b}}\right)$, and average cross-link density (ACD) can be 
Table 1

Chemical compositions (wt. \%) and density ( $\rho$ ) for prepared glass samples.

\begin{tabular}{|c|c|c|c|c|c|c|c|c|c|c|}
\hline Code & $\mathrm{TiO}_{2}$ & $\mathrm{Na}_{2} \mathrm{O}$ & $\mathrm{Bi}_{2} \mathrm{O}_{3}$ & $\mathrm{~B}_{2} \mathrm{O}_{3}$ & B & $\mathrm{O}$ & $\mathrm{Na}$ & $\mathrm{Ti}$ & $\mathrm{Bi}$ & $\rho\left(\mathrm{g} / \mathrm{cm}^{3}\right)$ \\
\hline TNB1 & 0 & 15 & 35 & 50 & 0.155285 & 0.419489 & 0.111279 & 0 & 0.313946 & 4.0251 \\
\hline TNB2 & 2.5 & 15 & 35 & 47.5 & 0.147521 & 0.412269 & 0.111279 & 0.014985 & 0.313946 & 4.0951 \\
\hline TNB3 & 5 & 15 & 35 & 45 & 0.139757 & 0.405048 & 0.111279 & 0.02997 & 0.313946 & 4.2521 \\
\hline TNB4 & 7.5 & 15 & 35 & 42.5 & 0.131993 & 0.397827 & 0.111279 & 0.044956 & 0.313946 & 4.4957 \\
\hline TNB5 & 10 & 15 & 35 & 40 & 0.124228 & 0.390606 & 0.111279 & 0.059941 & 0.313946 & 4.7951 \\
\hline
\end{tabular}

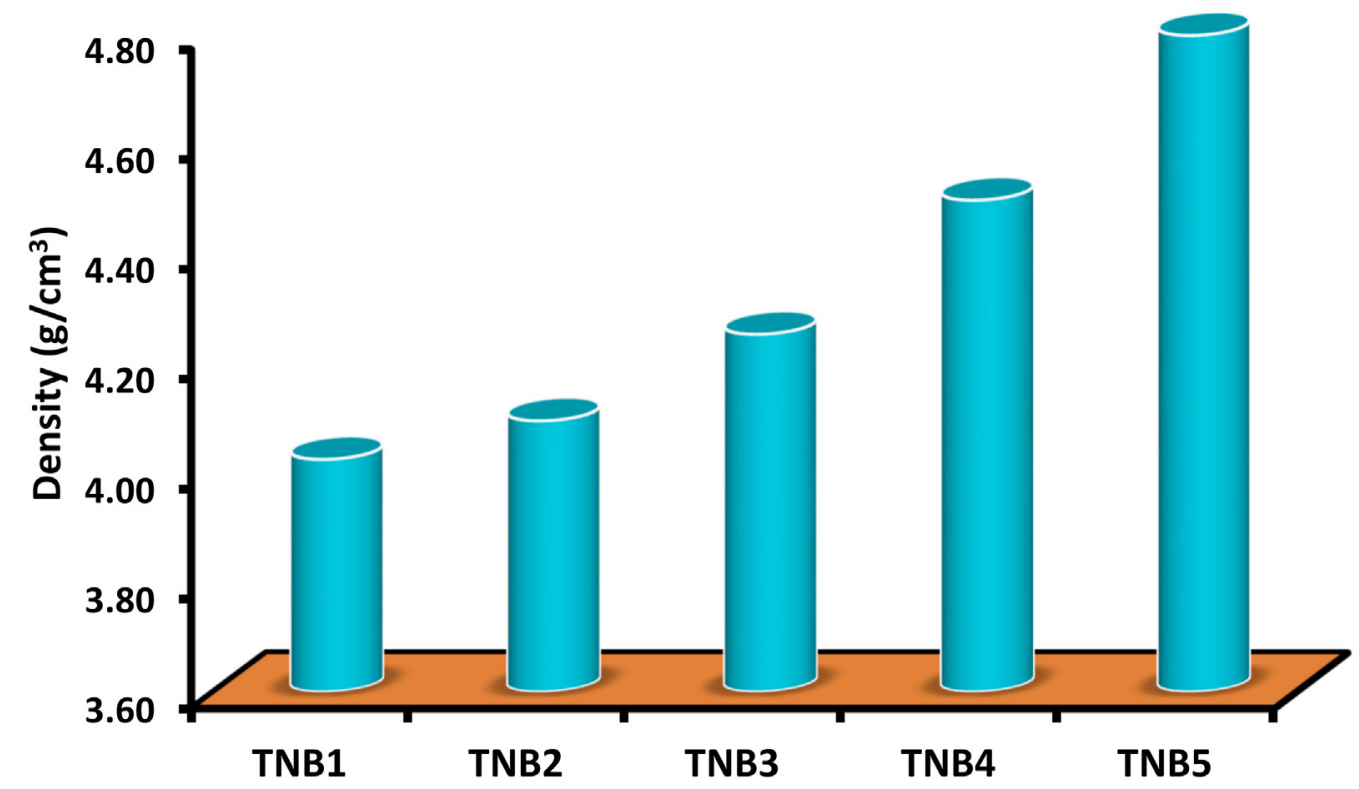

Fig. 4. Variations of experimental density $(\rho)$ results of glass samples.

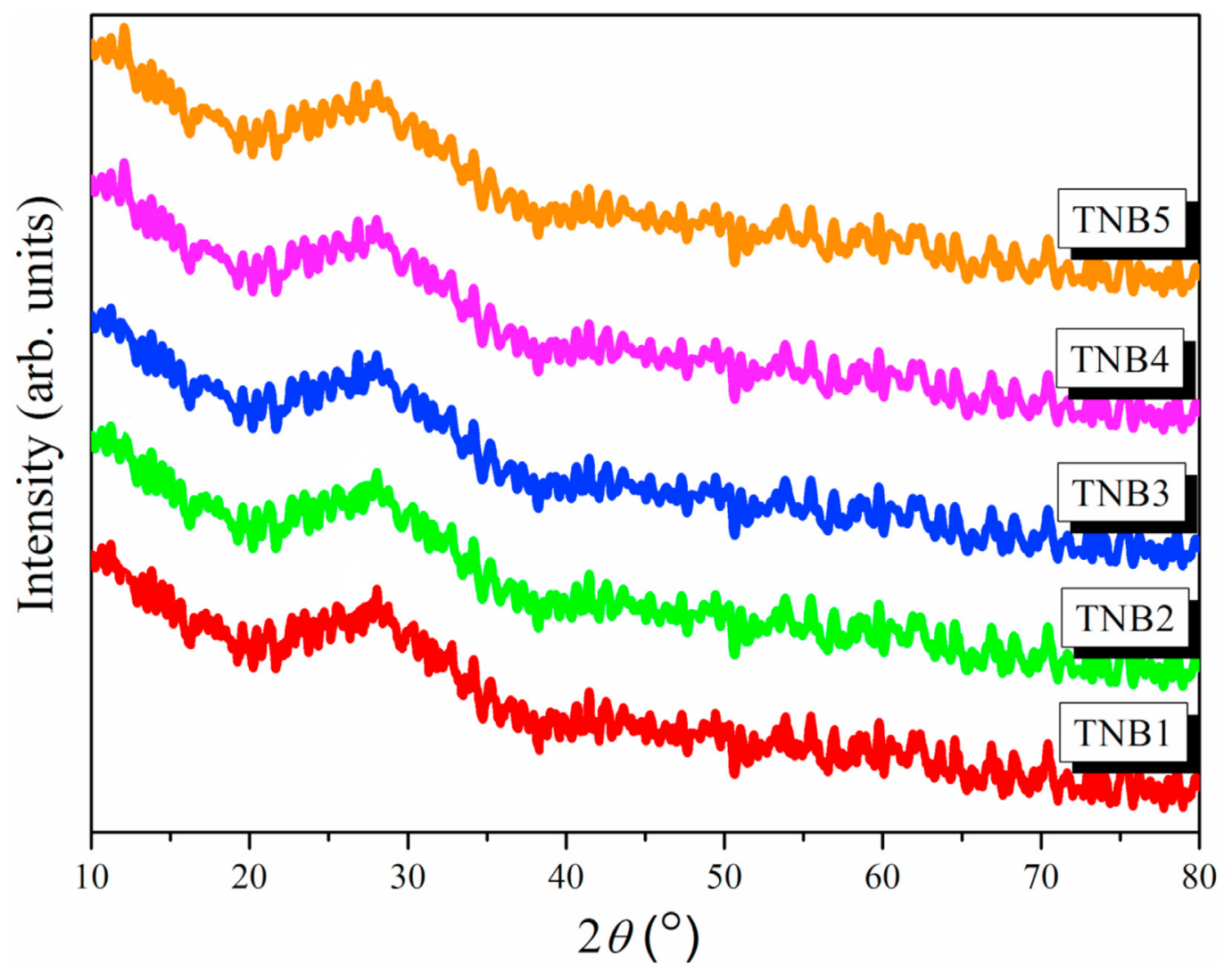

Fig. 5. X-ray diffraction patterns of prepare glass samples. 


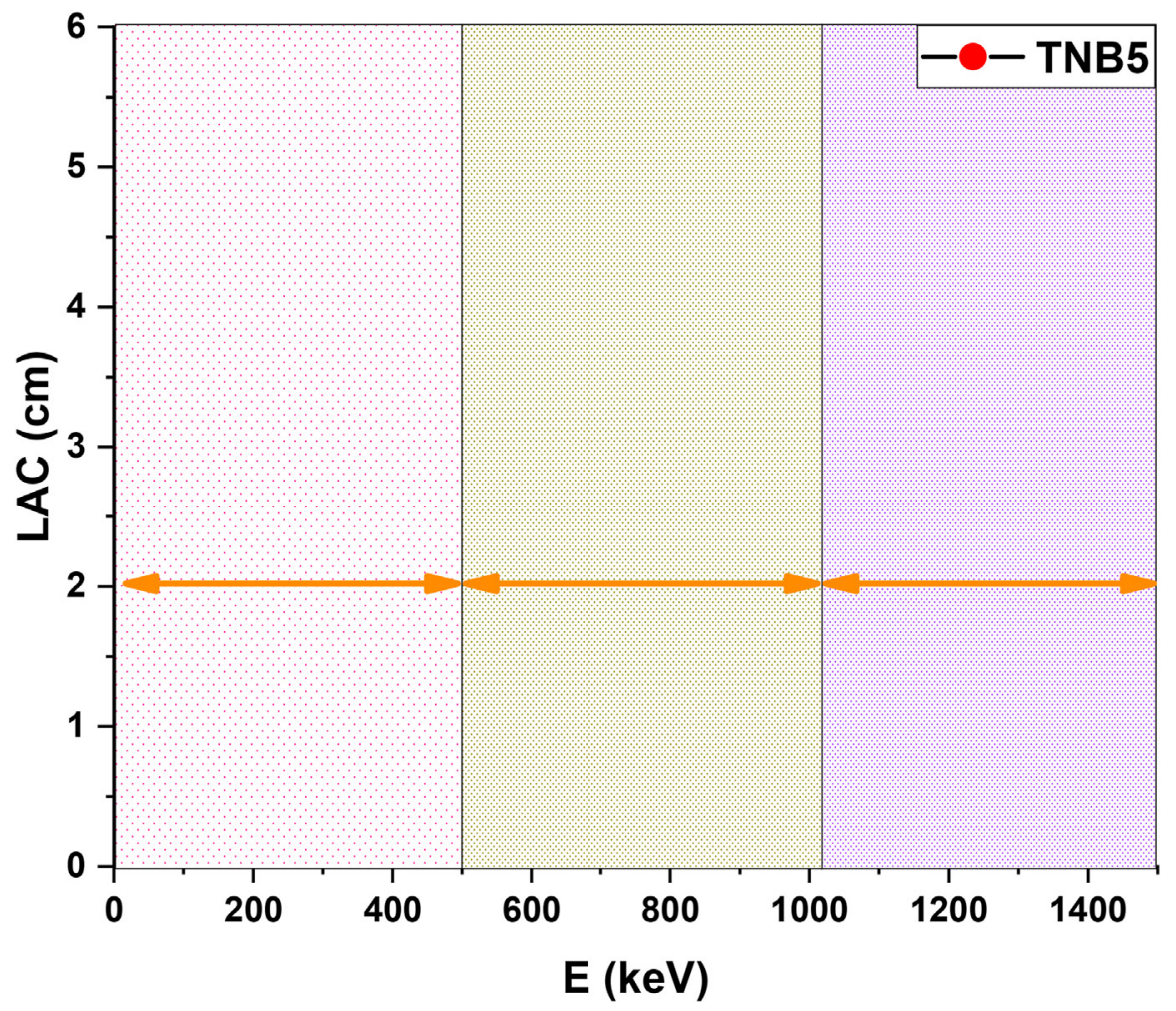

Fig. 6. Variation of experimental linear attenuation coefficient (LAC) values versus photon energy of TNB5 glass sample.

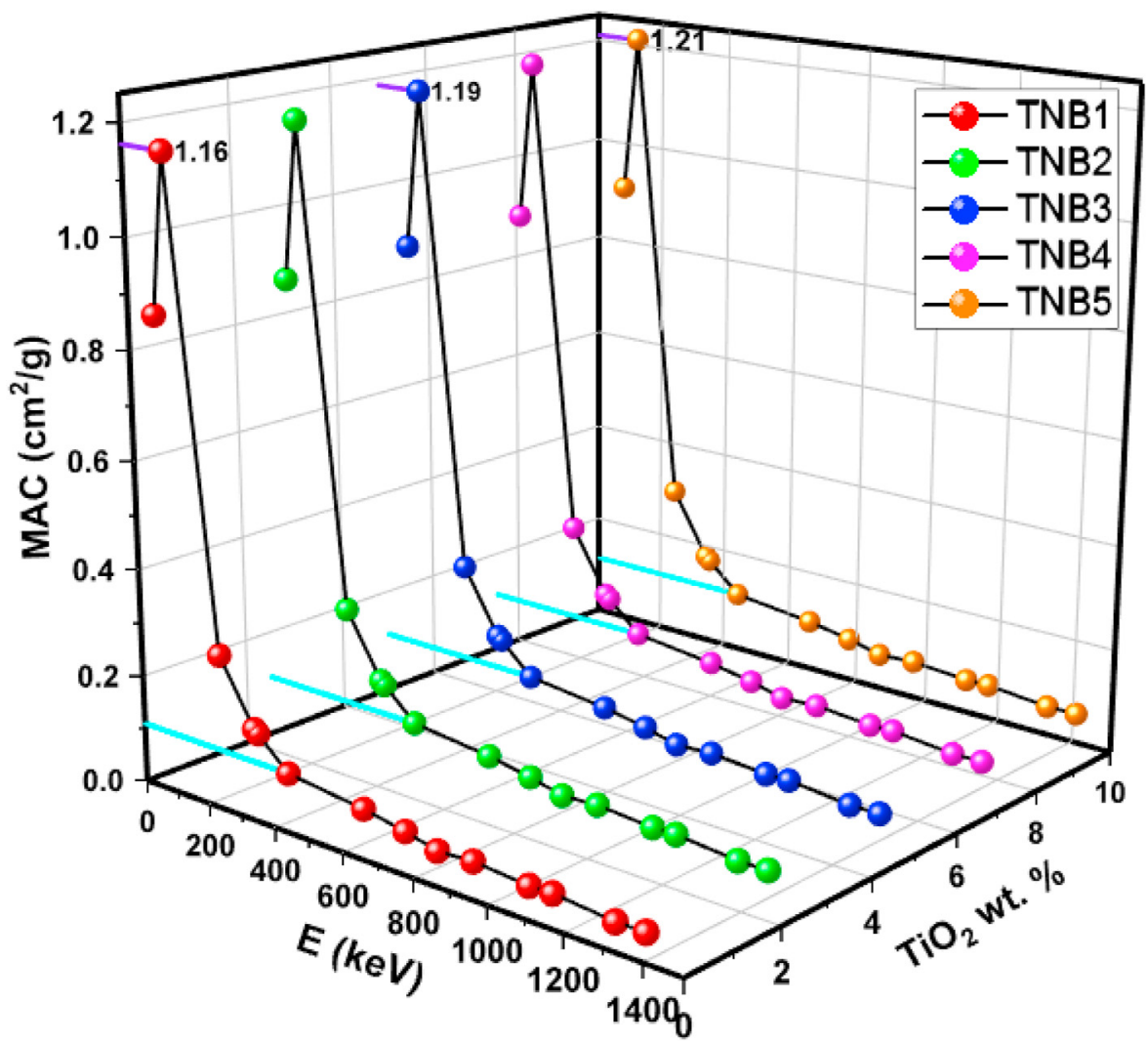

Fig. 7. Variation of experimental mass attenuation coefficient (MAC) values for the glass samples with photon energy for experimental results. 
Table 2

Experimental, XCOM and FLUKA results of mass attenuation coefficient (MAC) $\left(\mathrm{cm}^{2} / \mathrm{g}\right)$ for the prepared glasses.

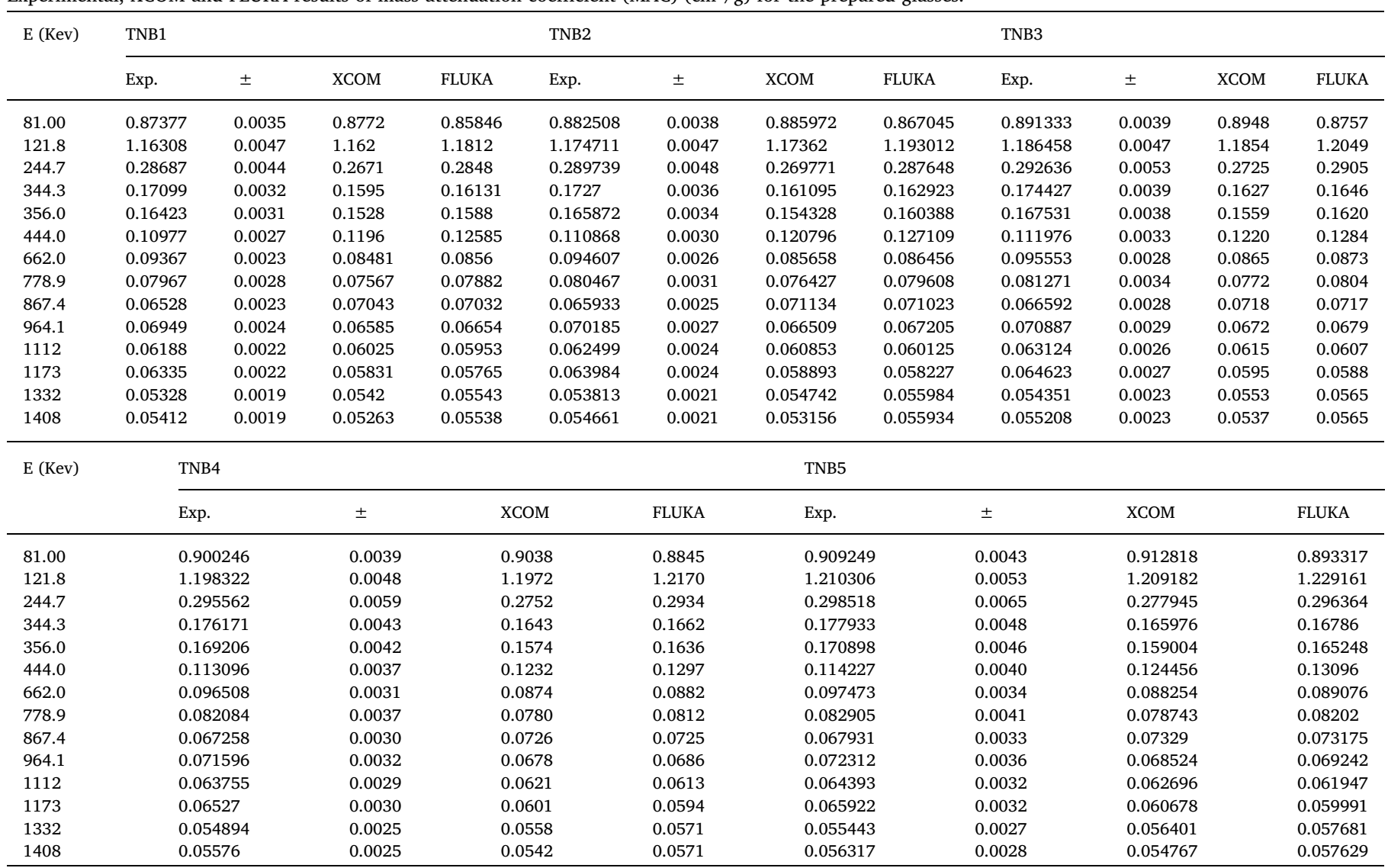

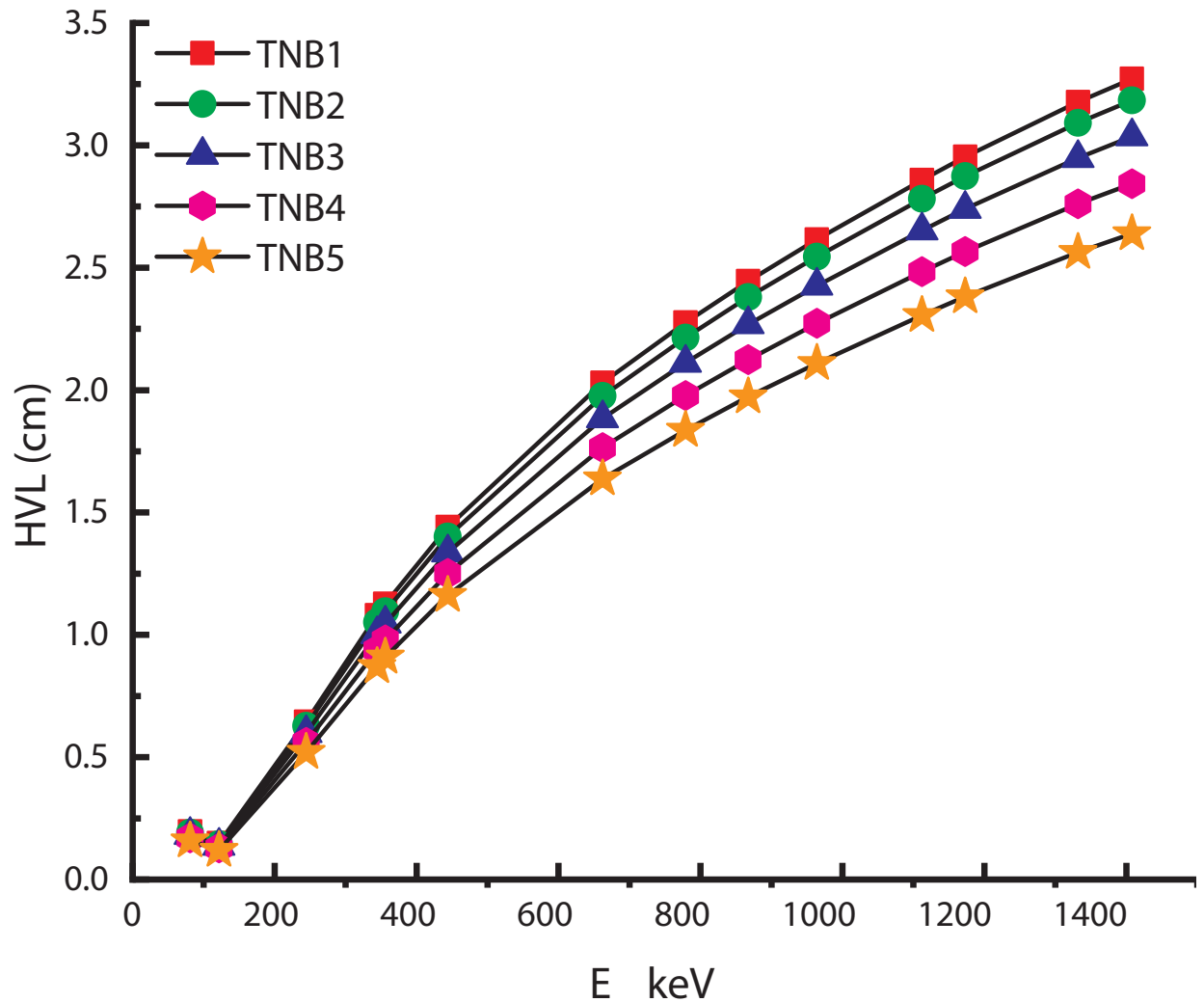

Fig. 8. Variation of experimental half-value layer (HVL) values with photon energy for the glass samples. 
Table 3

Experimental tenth value layer (TVL) and mean free path (MFP) results of the prepared glasses.

\begin{tabular}{|c|c|c|c|c|c|c|c|c|c|c|}
\hline \multirow[t]{2}{*}{ E (Kev) } & \multicolumn{5}{|l|}{ TVL } & \multicolumn{5}{|l|}{ MFP } \\
\hline & TNB1 & TNB2 & TNB3 & TNB4 & TNB5 & TNB1 & TNB2 & TNB3 & TNB4 & TNB5 \\
\hline 81.00 & 0.65 & 0.63 & 0.61 & 0.57 & 0.53 & 0.28 & 0.28 & 0.26 & 0.25 & 0.23 \\
\hline 121.8 & 0.49 & 0.48 & 0.46 & 0.43 & 0.40 & 0.21 & 0.21 & 0.20 & 0.19 & 0.17 \\
\hline 244.7 & 2.14 & 2.08 & 1.99 & 1.86 & 1.73 & 0.93 & 0.91 & 0.86 & 0.81 & 0.75 \\
\hline 344.3 & 3.59 & 3.49 & 3.33 & 3.12 & 2.89 & 1.56 & 1.52 & 1.45 & 1.35 & 1.26 \\
\hline 356.0 & 3.74 & 3.64 & 3.47 & 3.25 & 3.02 & 1.63 & 1.58 & 1.51 & 1.41 & 1.31 \\
\hline 444.0 & 4.78 & 4.65 & 4.44 & 4.16 & 3.86 & 2.08 & 2.02 & 1.93 & 1.81 & 1.68 \\
\hline 662.0 & 6.75 & 6.56 & 6.26 & 5.86 & 5.44 & 2.93 & 2.85 & 2.72 & 2.55 & 2.36 \\
\hline 778.9 & 7.56 & 7.36 & 7.02 & 6.57 & 6.10 & 3.28 & 3.20 & 3.05 & 2.85 & 2.65 \\
\hline 867.4 & 8.12 & 7.90 & 7.54 & 7.06 & 6.55 & 3.53 & 3.43 & 3.27 & 3.07 & 2.85 \\
\hline 964.1 & 8.69 & 8.45 & 8.06 & 7.55 & 7.01 & 3.77 & 3.67 & 3.50 & 3.28 & 3.04 \\
\hline 1112 & 9.49 & 9.24 & 8.81 & 8.25 & 7.66 & 4.12 & 4.01 & 3.83 & 3.58 & 3.33 \\
\hline 1173 & 9.81 & 9.55 & 9.10 & 8.53 & 7.91 & 4.26 & 4.15 & 3.95 & 3.70 & 3.44 \\
\hline 1332 & 10.55 & 10.27 & 9.79 & 9.17 & 8.51 & 4.58 & 4.46 & 4.25 & 3.98 & 3.70 \\
\hline 1408 & 10.87 & 10.58 & 10.09 & 9.45 & 8.77 & 4.72 & 4.59 & 4.38 & 4.10 & 3.81 \\
\hline
\end{tabular}
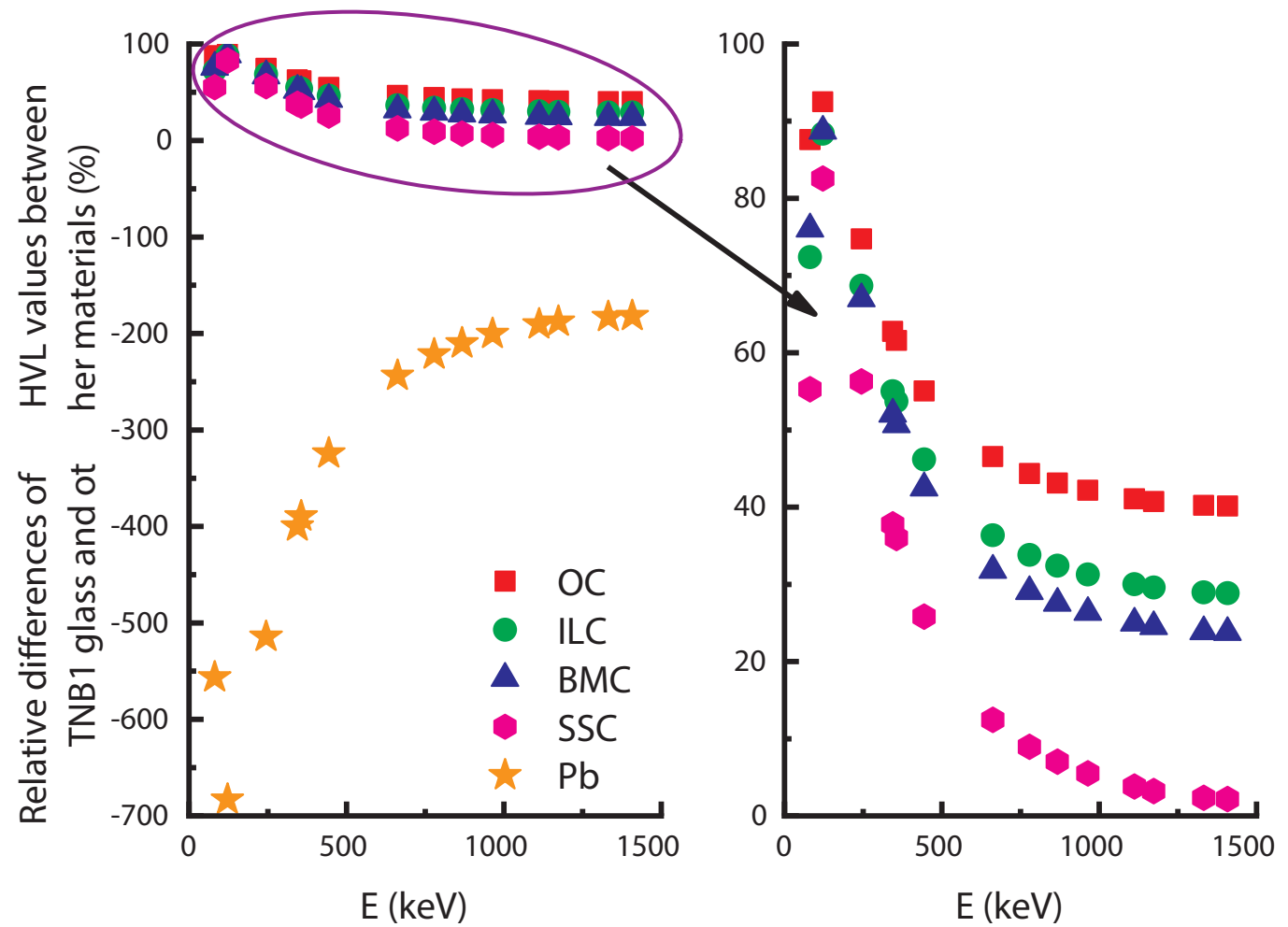

Fig. 9. Relative differences of HVL values between TNB1 glass and other materials (\%).

utilized to calculate some essential physical parameters of the proposed glass shield according to the following formulas [28]:

$M O V=V_{m}\left(\frac{1}{\sum_{i} x_{i} n_{i}}\right)$

$O P D=1000 N\left(\frac{\rho}{M}\right)$

$n_{b}=\frac{N_{A}}{V_{m}} \sum_{i}\left(n_{f}\right)_{i} x_{i}$

$A C D=\frac{\sum_{i}\left(n_{c}\right)_{i}\left(N_{c}\right)_{i}}{\sum_{i} x_{i}\left(N_{c}\right)_{i}}$, where $\quad\left(n_{c}=n_{f}-2\right)$

where $V_{m}, X_{i}, M, n_{i}, n_{f}$, and $N_{C}$ are the molar volume, molar fraction of the ith component, molecular weight, number of oxygen atoms in each constituent oxide, coordination numbers, and the number of cations per glass formula unit, respectively. Using packing density $\left(\mathrm{V}_{\mathrm{t}}\right)$ and dissociation energy per unit volume $\left(\mathrm{G}_{\mathrm{t}}\right)$, Makishima and Mackenzie suggested a model to evaluate the values of Young's modulus (Y), the bulk (k), shear (G), and longitudinal (L) moduli, and Poisson's ratio ( $\sigma$ ) [29]:

$V_{t}=\frac{1}{V_{m}} \sum_{i} x_{i} V_{i}$

$V_{i}=N_{A}\left(\frac{4 \pi}{3}\right)\left(x R_{A}^{3}+y R_{O}^{3}\right)$

$Y=9.38 V_{t} G_{t}$

$K=10 V_{t}^{2} G_{t}$

$G=\frac{30 V_{t}^{2} G_{t}}{\left(10.2 V_{t}-1\right)}$ 


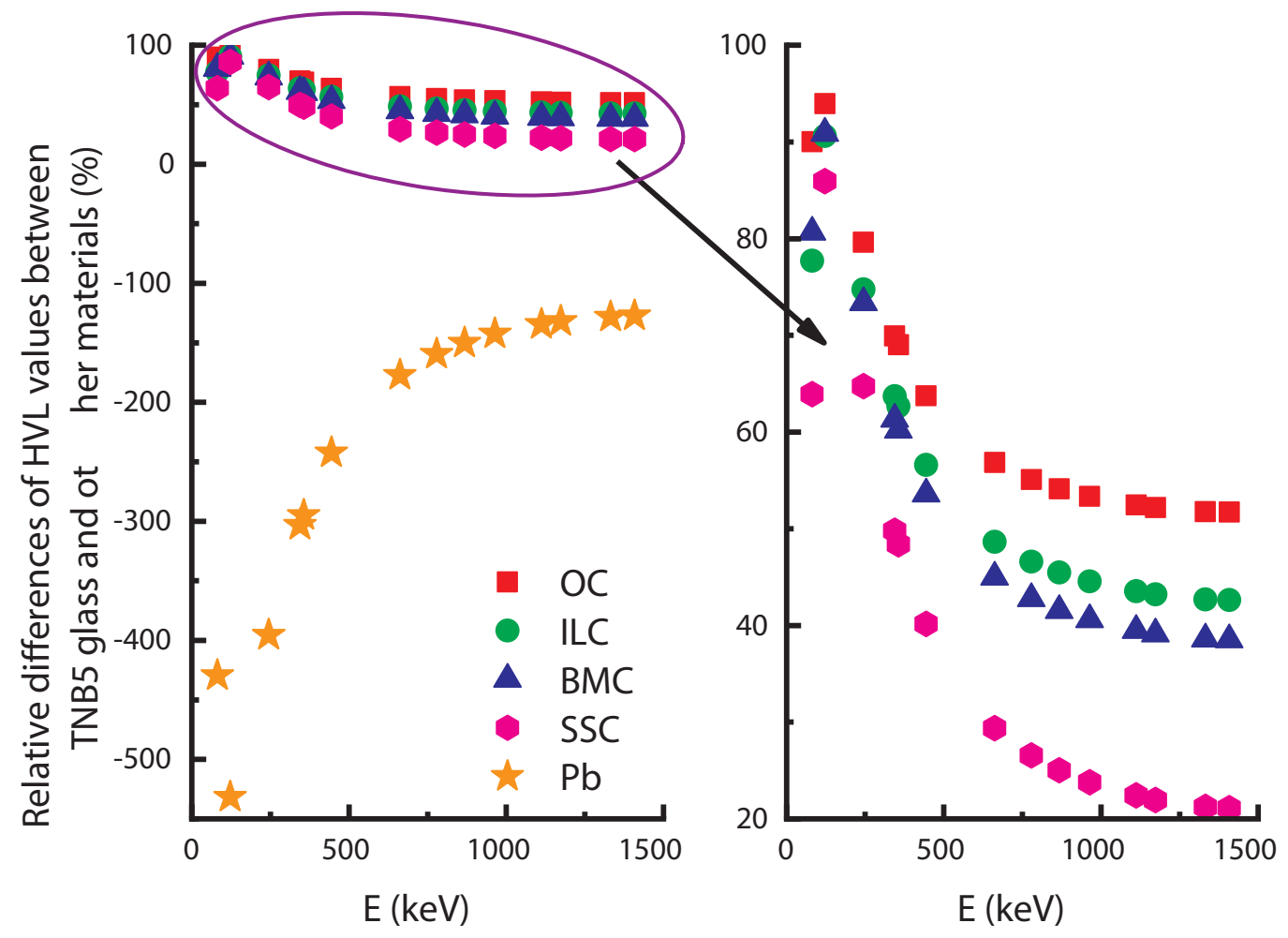

Fig. 10. Relative differences of HVL values between TNB5 glass and other materials (\%).

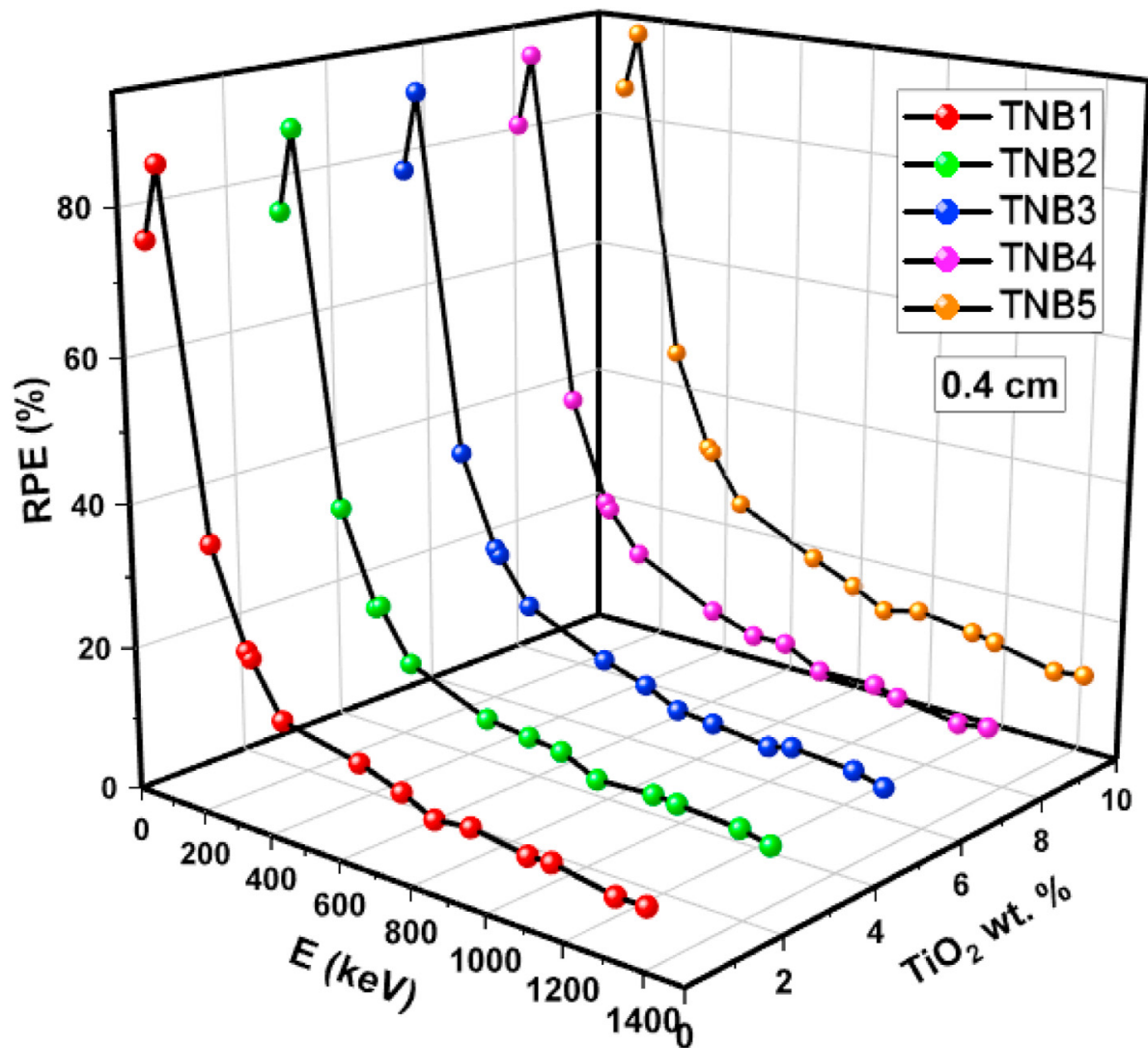

Fig. 11. RPE values versus photon energy for prepared glass samples. 


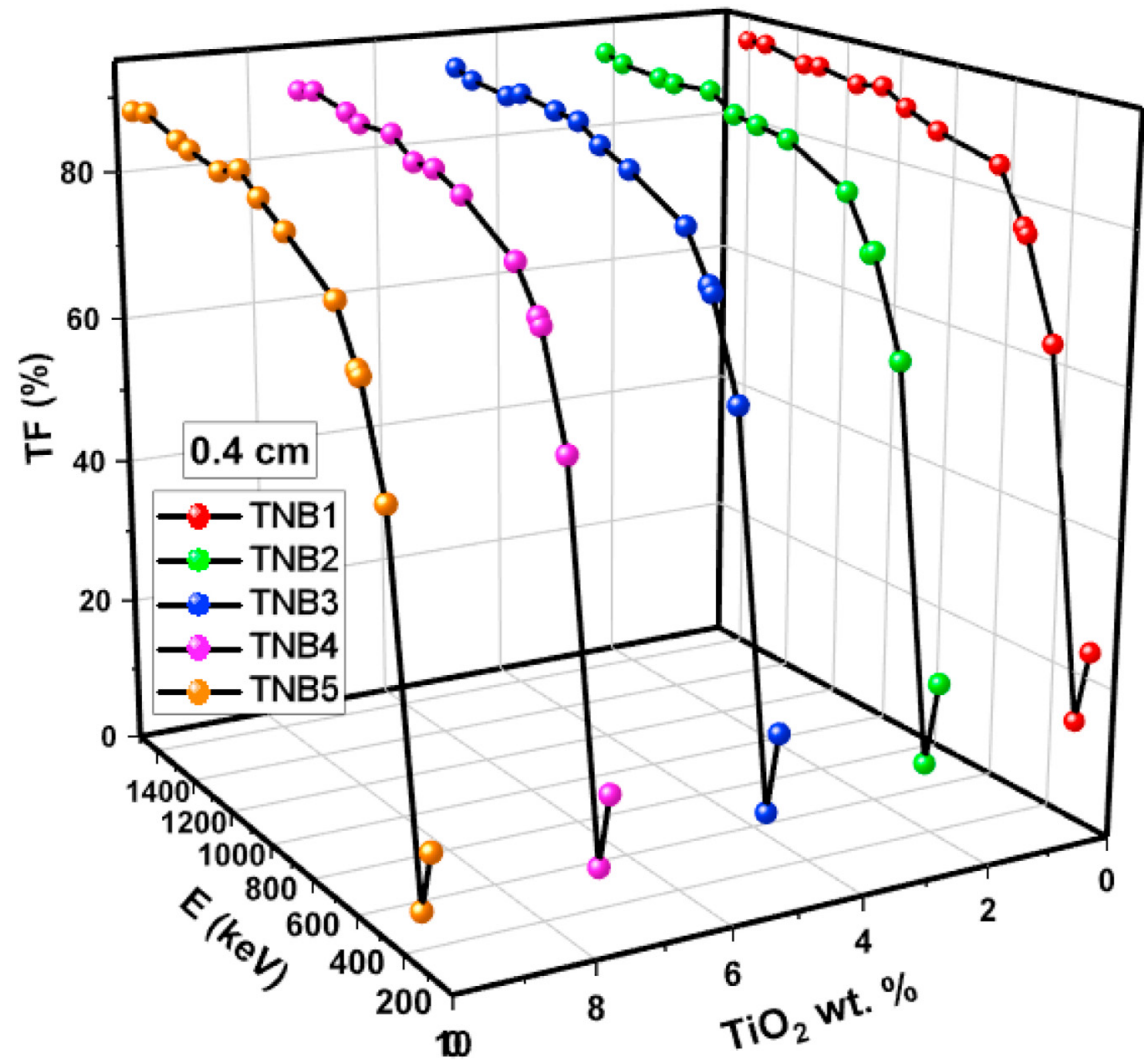

Fig. 12. TF values versus photon energy for prepared glass samples.
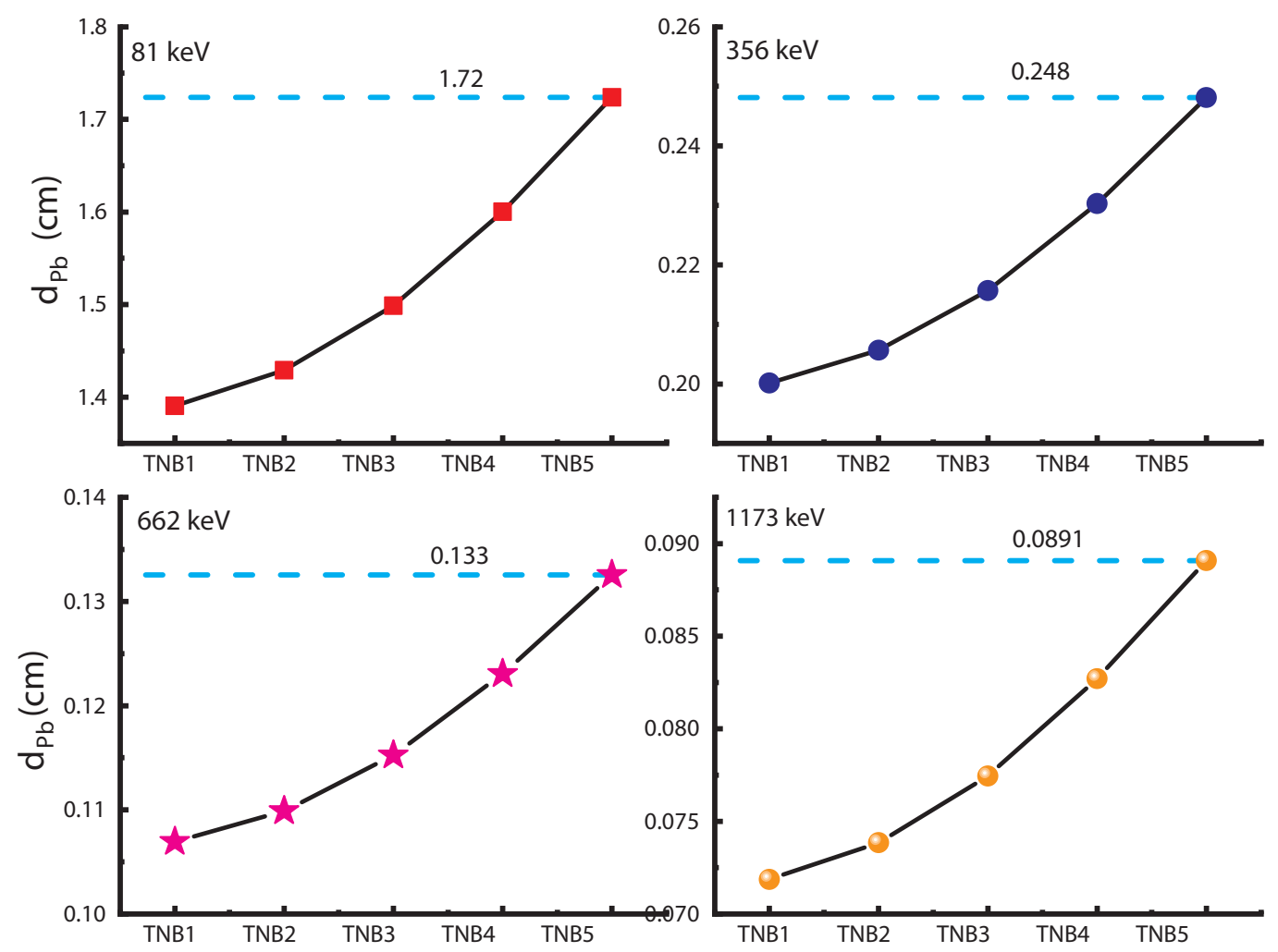

Fig. 13. Lead equivalent $\left(\mathrm{d}_{\mathrm{Pb}}\right)$ values of TNB glass samples at 81, 356, 662 and $1173 \mathrm{keV}$. 
Table 4

Experimental lead equivalent values of TNB glass samples.

\begin{tabular}{llllll}
\hline E $(\mathrm{keV})$ & TNB1 & TNB2 & TNB3 & TNB4 & TNB5 \\
\hline 81.00 & 1.39 & 1.43 & 1.50 & 1.60 & 1.72 \\
121.8 & 1.72 & 1.76 & 1.85 & 1.97 & 2.13 \\
244.7 & 0.36 & 0.37 & 0.39 & 0.42 & 0.45 \\
344.3 & 0.21 & 0.22 & 0.23 & 0.24 & 0.26 \\
356.0 & 0.20 & 0.21 & 0.22 & 0.23 & 0.25 \\
444.0 & 0.15 & 0.16 & 0.17 & 0.18 & 0.19 \\
662.0 & 0.11 & 0.11 & 0.12 & 0.12 & 0.13 \\
778.9 & 0.09 & 0.10 & 0.10 & 0.11 & 0.12 \\
867.4 & 0.09 & 0.09 & 0.09 & 0.10 & 0.11 \\
964.1 & 0.08 & 0.08 & 0.09 & 0.09 & 0.10 \\
1112 & 0.07 & 0.08 & 0.08 & 0.09 & 0.09 \\
1173 & 0.07 & 0.07 & 0.08 & 0.08 & 0.09 \\
1332 & 0.07 & 0.07 & 0.07 & 0.08 & 0.08 \\
1408 & 0.06 & 0.07 & 0.07 & 0.07 & 0.08 \\
\hline
\end{tabular}

$L=K\left(\frac{4}{3}\right) G$

$\sigma=0.5-\left(\frac{1}{7.2 V_{t}}\right)$

where $R_{A}$ and $R_{O}$ are the ionic radius of metal and oxygen, respectively.

\section{Results and discussion}

\subsection{Physical properties}

The chemical composition and density results of the TNB1, TNB2, TNB3, TNB4, and TNB5 glass samples are listed in Table 1. The density results of the studied glass samples as $\mathrm{TiO}_{2}$ content was increased are shown in Fig. 4. The density of the samples increases as the $\mathrm{TiO}_{2}$
Table 5

Buildup factor (BF) values of TNB glass samples.

\begin{tabular}{llllll}
\hline E (Kev) & TNB1 & TNB2 & TNB3 & TNB4 & TNB5 \\
\hline 81.00 & 1.005538 & 1.005691 & 1.005969 & 1.006375 & 1.006869 \\
121.8 & 0.998263 & 0.998215 & 0.998128 & 0.998001 & 0.997847 \\
244.7 & 0.968671 & 0.967821 & 0.96628 & 0.964033 & 0.961309 \\
344.3 & 0.981671 & 0.98117 & 0.980262 & 0.978937 & 0.977328 \\
356.0 & 0.981766 & 0.981268 & 0.980364 & 0.979046 & 0.977445 \\
444.0 & 1.015953 & 1.016396 & 1.017202 & 1.01838 & 1.019814 \\
662.0 & 0.985836 & 0.985449 & 0.984745 & 0.983718 & 0.982472 \\
778.9 & 0.993581 & 0.993404 & 0.993084 & 0.992616 & 0.992048 \\
867.4 & 1.008326 & 1.008557 & 1.008975 & 1.009587 & 1.010332 \\
964.1 & 0.994157 & 0.993996 & 0.993704 & 0.993279 & 0.992761 \\
1112 & 0.997379 & 0.997307 & 0.997176 & 0.996985 & 0.996752 \\
1173 & 0.991918 & 0.991696 & 0.991294 & 0.990706 & 0.989991 \\
1332 & 1.001482 & 1.001523 & 1.001597 & 1.001706 & 1.001838 \\
1408 & 0.997604 & 0.997538 & 0.997418 & 0.997243 & 0.99703 \\
\hline
\end{tabular}

concentration increases. The increase in glass density is due to the significant difference between the densities and molecular masses of $\mathrm{B}_{2} \mathrm{O}_{3}\left(\rho=2.55 \mathrm{~g} / \mathrm{cm}^{3}\right.$ and $\left.\mathrm{M} . \mathrm{W}=69.62 \mathrm{~g} / \mathrm{mol}\right)$ and $\mathrm{TiO}_{2}(\rho=4.23 \mathrm{~g} /$ $\mathrm{cm}^{3}$ and $\mathrm{M}$. W $=79.866 \mathrm{~g} / \mathrm{mol}$ ). Accordingly, an increased $\mathrm{TiO}_{2}$ substitution ratio fills in the interstitial spaces with the higher density and molecular weight of $\mathrm{TiO}_{2}$. The X-ray diffraction patterns of the quenched $\mathrm{xTiO}_{2}-15 \mathrm{Na}_{2} \mathrm{O}-30 \mathrm{Bi}_{2} \mathrm{O}_{3}-(50-\mathrm{x}) \mathrm{B}_{2} \mathrm{O}_{3}$ samples displayed no crystalline peaks, as shown in Fig. 5. An expanded hump confirming an amorphous structure was observed for all samples at $2 \theta \sim 28^{\circ}-30^{\circ}$. The increase in the $\mathrm{TiO}_{2}$ content substitution ratio did not affect the amorphous nature of the glass samples.

\subsection{Gamma shielding parameters}

The LAC experimental results for the TNB5 sample (an example) are

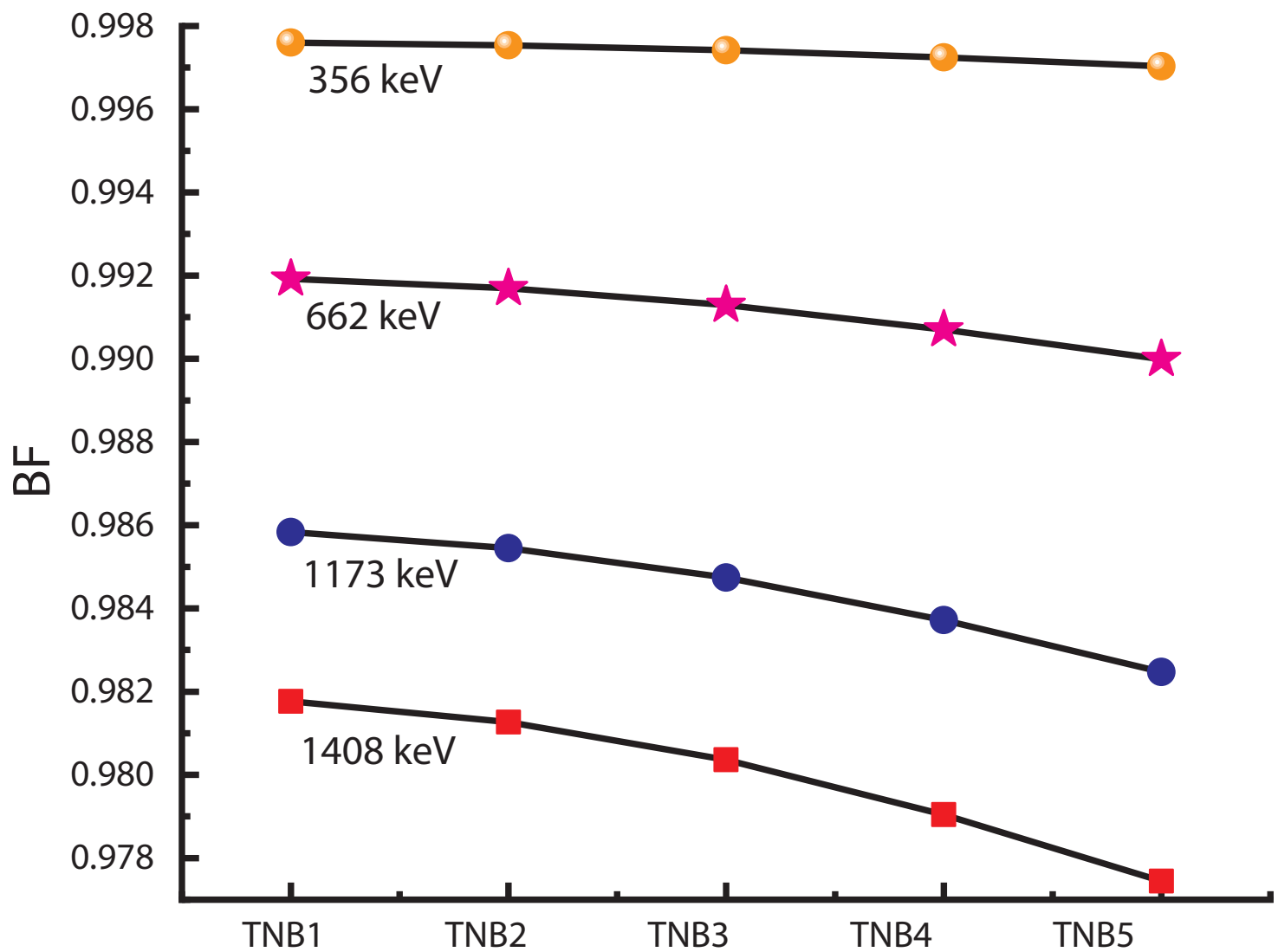

Fig. 14. Buildup factor (BF) values of TNB glass samples ate 356, 66, 1173 and $1408 \mathrm{keV}$. 


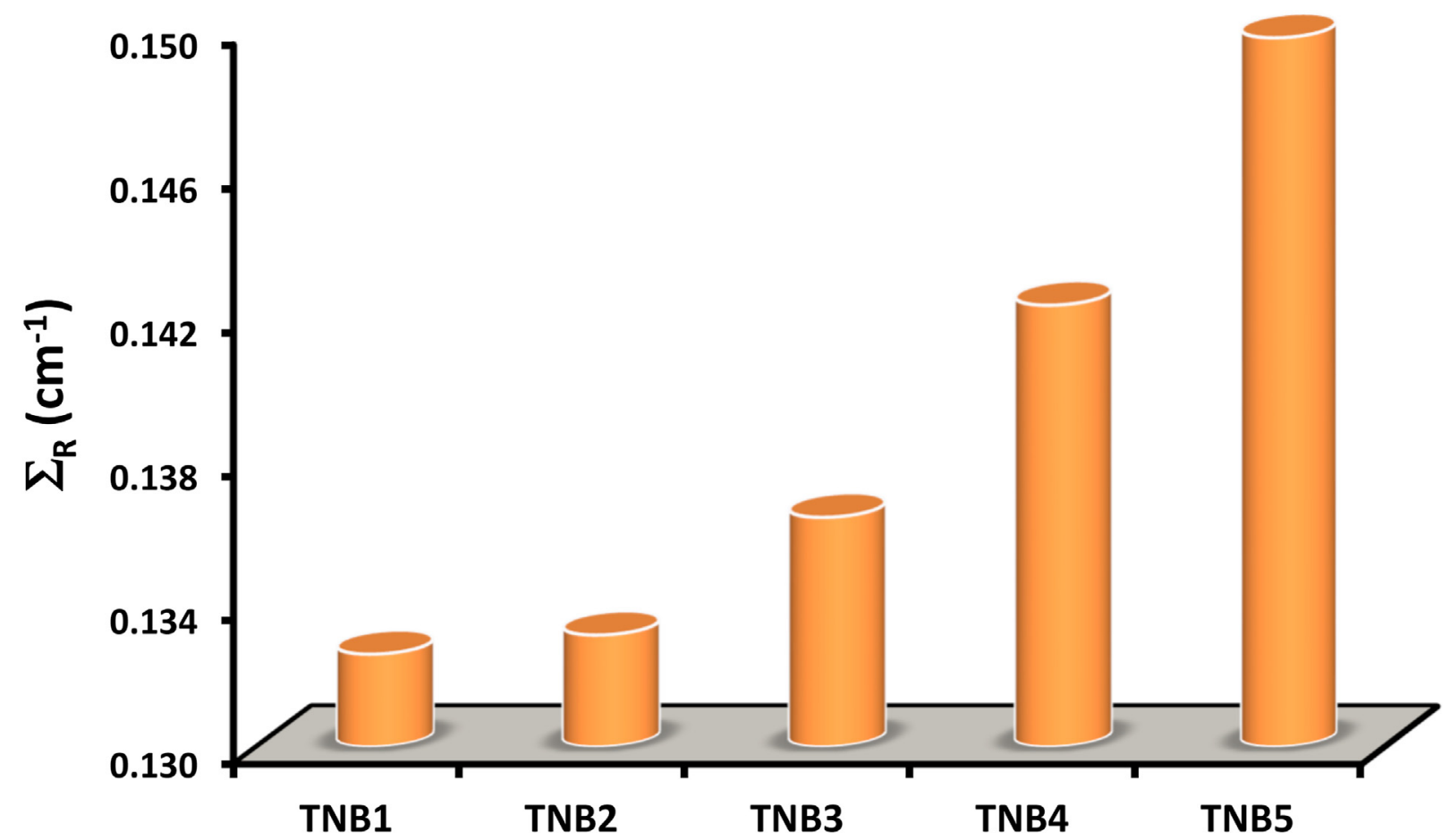

Fig. 15. Fast neutron removal cross sections $\left(\Sigma_{R}\right)$ values for the selected glass samples.

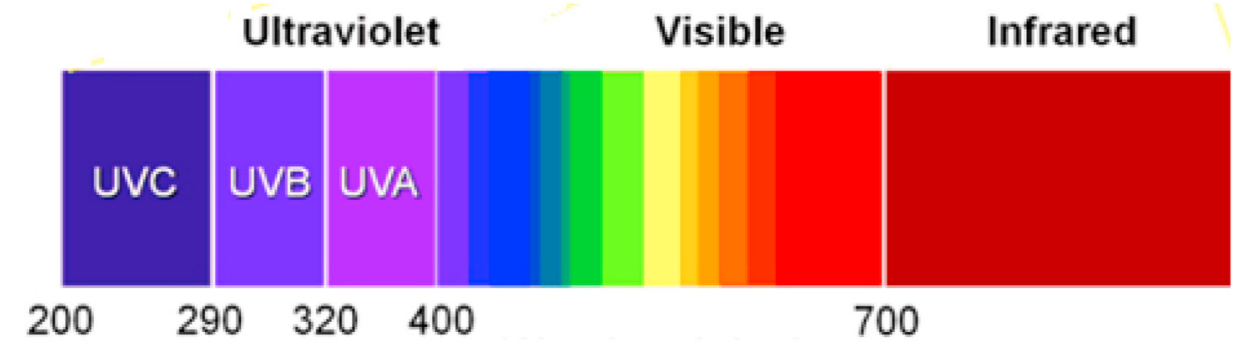

Fig. 16. Ultraviolet, visible and infrared light range.

plotted for the energy range of $81-1408 \mathrm{keV}$ in Fig. 6. The LAC experimental values for the TNB5 sample (which has the highest amount of $\mathrm{TiO}_{2}$ ) increase as energy (E) increases depending on the kind of interaction process, with a sharp peak due to the k-absorption edge of Bi. Photoelectric absorption (PEA), Compton scattering (CS), and pair production (PP) processes predominate at $\mathrm{E}<511 \mathrm{keV}$, $511<\mathrm{E}<1022 \mathrm{keV}$, and $\mathrm{E}>1022 \mathrm{keV}$, respectively [15]. The MAC experimental results for the TNB1, TNB2, TNB3, TNB4, and TNB5 samples are plotted for the energy range $81-1408 \mathrm{keV}$ in Fig. 7. In general, the MAC experimental results decrease as $\mathrm{E}$ increases from 81 to $1408 \mathrm{keV}$ and increase as $\mathrm{TiO}_{2}$ concentration increases from 0 to $10 \mathrm{wt} \%$. Depending on PEA, CS, and PP processes, the MAC experimental values declined against photon energy (identical to LAC behavior) [14]. The MAC experimental results for the TNB1, TNB2, TNB3, TNB4, and TNB5 samples were simulated using the FLUKA code and calculated theoretically with the XCOM database (Table 2). The MAC experimental results of the TNB1, TNB2, TNB3, TNB4, and TNB5 samples agree very well with the FLUKA code and the XCOM database (Table 2). The MAC experimental uncertainties were calculated by:

$\Delta(M A C)=\frac{1}{t} \sqrt{\left(\frac{\Delta I_{O}}{I_{O}}\right)^{2}+\left(\frac{\Delta I}{I}\right)^{2}+\left(\ln \frac{I_{O}}{I}\right)^{2}\left(\frac{\Delta t}{t}\right)^{2}}$

Using the LAC experimental results, the half-value layer (HVL), tenth-value layer (TVL), and mean free path (MFP) were calculated for the TNB1, TNB2, TNB3, TNB4, and TNB5 samples at an E of
81-1408 keV (Fig. 8 and Table 3). The HVL experimental results increase as E increases from 81 to $1408 \mathrm{keV}$, indicating that radiation can easily penetrate through the glass samples when E increases. The TNB5 (10 TiO2 wt. \%) sample has the lowest HVL, TVL, and MFP values of all the samples, while the TNB1 (0 TiO2 wt. \%) sample has the highest such values due to the fact that it has the lowest density ( $\rho$ ). Thus, increasing the Ti concentration leads to an increase in the $\rho$ results of the glass samples, which leads to an increase in their MAC execution In Figs. 9 and 10, the HVL results of the TNB1 and TNB5 samples are compared with the HVL results of ordinary (OC), ilmenite-limonite (ILC), basalt-magnetite (BMC), and steel-scrap (SSC) concretes [30], as well as lead $(\mathrm{Pb})$. As shown in these figures, the HVL results of the TNB1 and TNB5 samples are lower than those for OC, ILC, BMC, and SSC. The HVL results of the TNB1 and TNB5 samples are higher than that for $\mathrm{Pb}$. The addition of $\mathrm{TiO}_{2}$ also increases the relative difference between the glass samples and concretes and decreases the relative difference between the glass samples and $\mathrm{Pb}$. For example, at $662 \mathrm{keV}$, the relative difference between BMC and the samples increases from 31 to $45 \%$ due to the $\mathrm{TiO}_{2}$ concentration increasing from 0 to $10 \mathrm{wt} \%$. This means that the HVL results of TNB5 are lower than the HVL results of BMC at $45 \%$. The relative difference between $\mathrm{Pb}$ and the samples decreases from -244 to $-177 \%$ due to the $\mathrm{TiO}_{2}$ concentration increasing from 0 to $10 \mathrm{wt} \%$.

The RPE and TF experimental results for the TNB1, TNB2, TNB3, TNB4, and TNB5 samples in the selected energy range of 81-1408 keV 


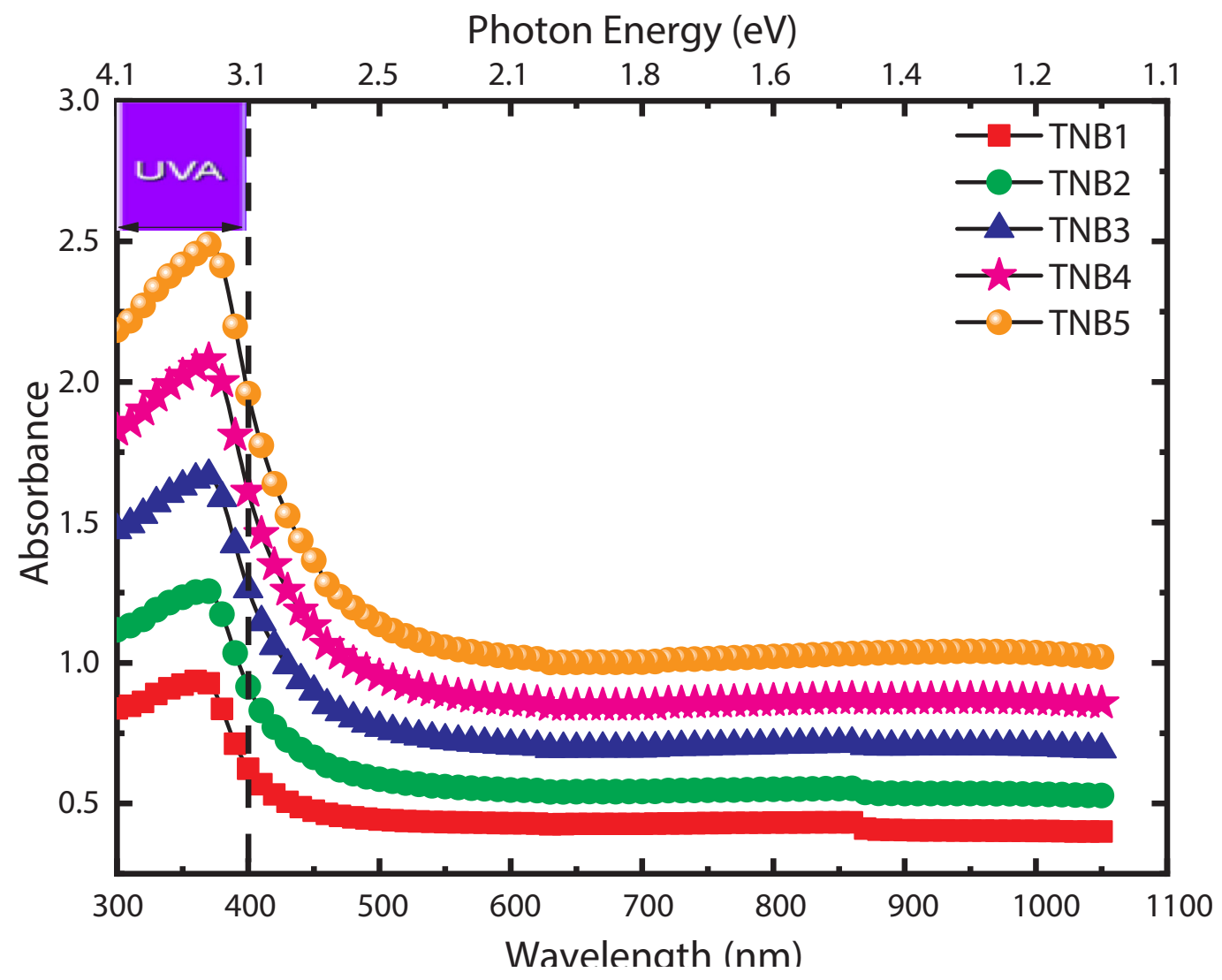

Fig. 17. Absorbance spectra as a function of wavelength for prepared glass samples.

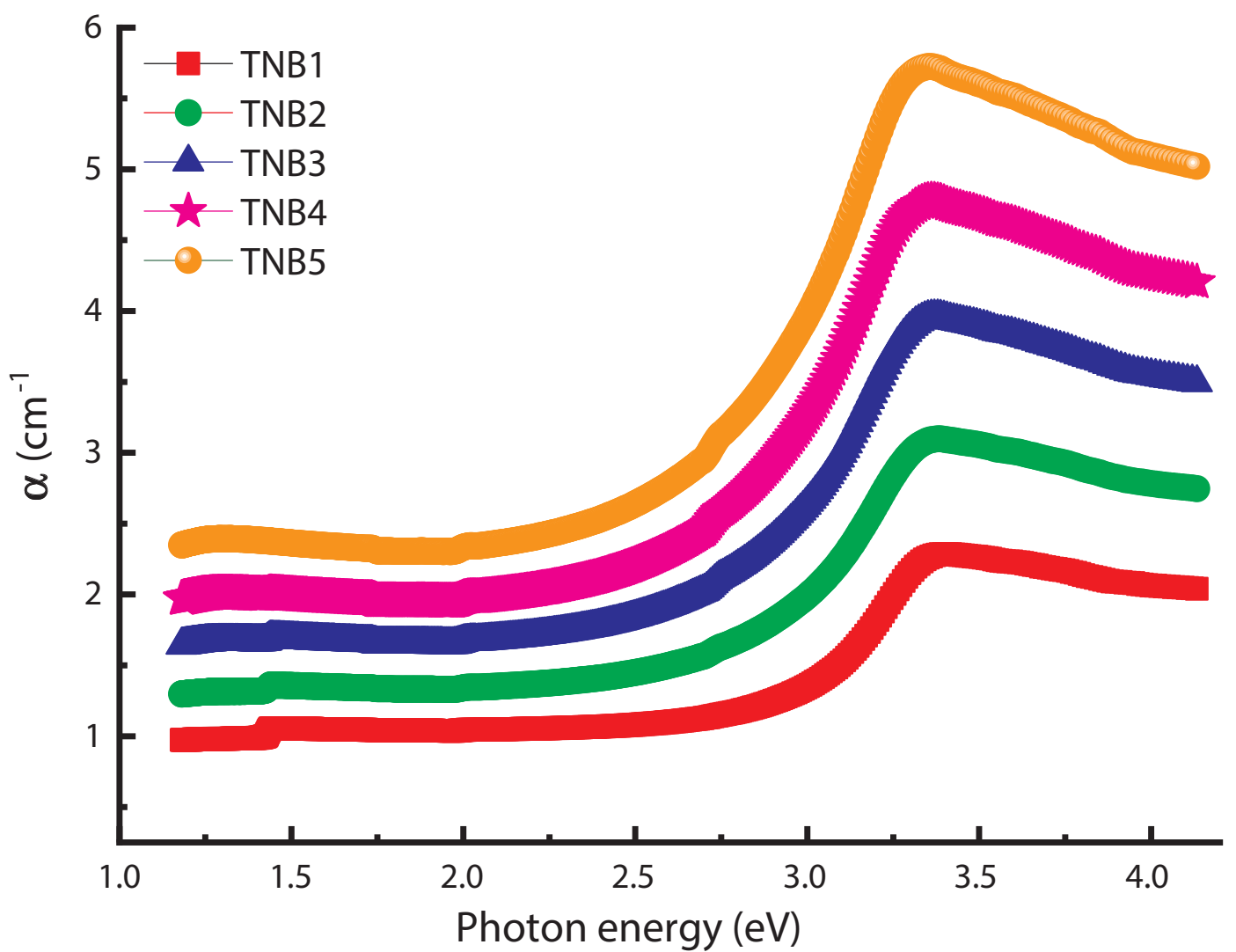

Fig. 18. Absorption coefficient $(\alpha)$ versus incident photon energy for prepared glass samples. 


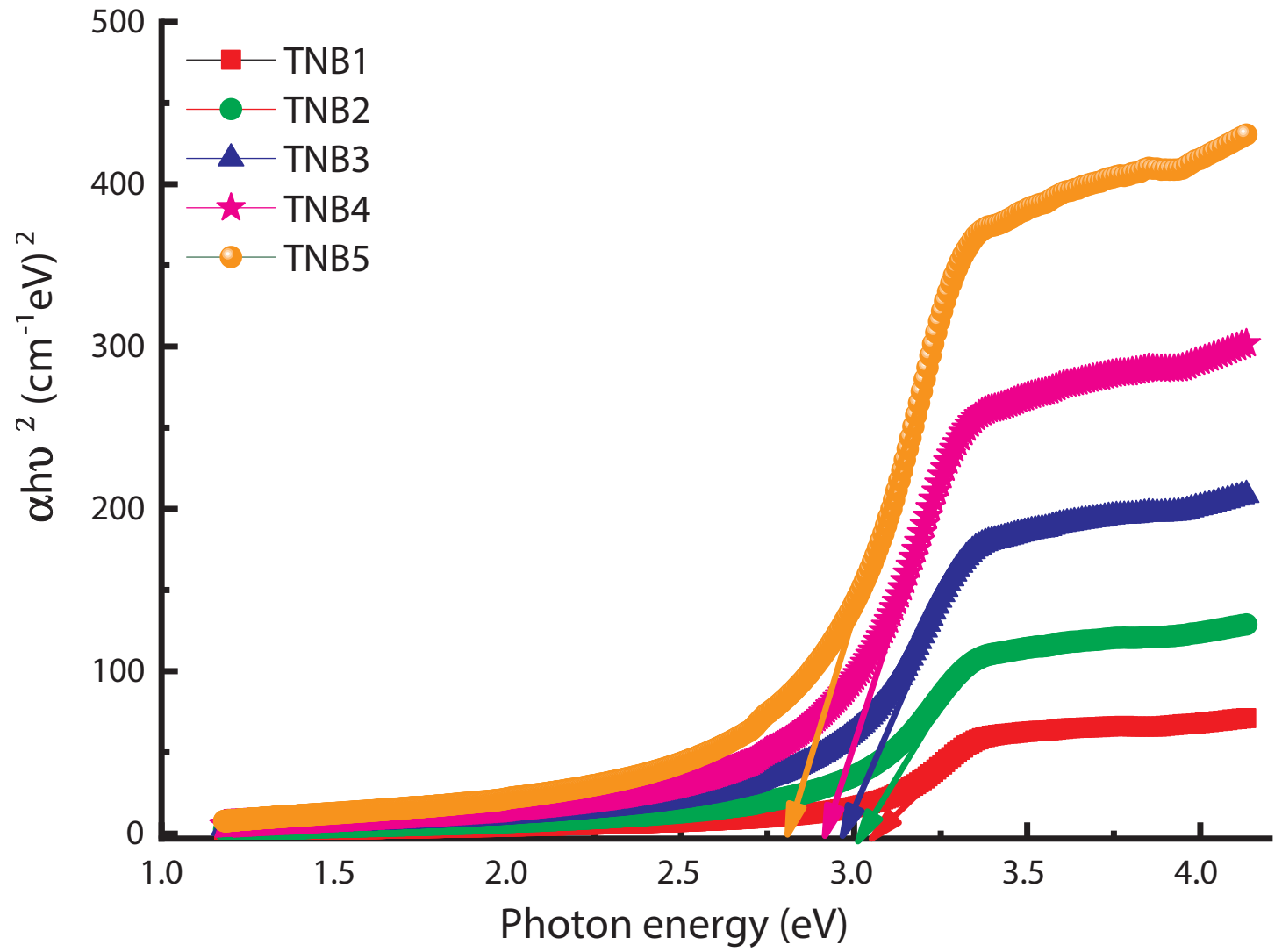

Fig. 19. $(\alpha h \nu)^{2}$ versus incident photon energy for prepared glass samples.

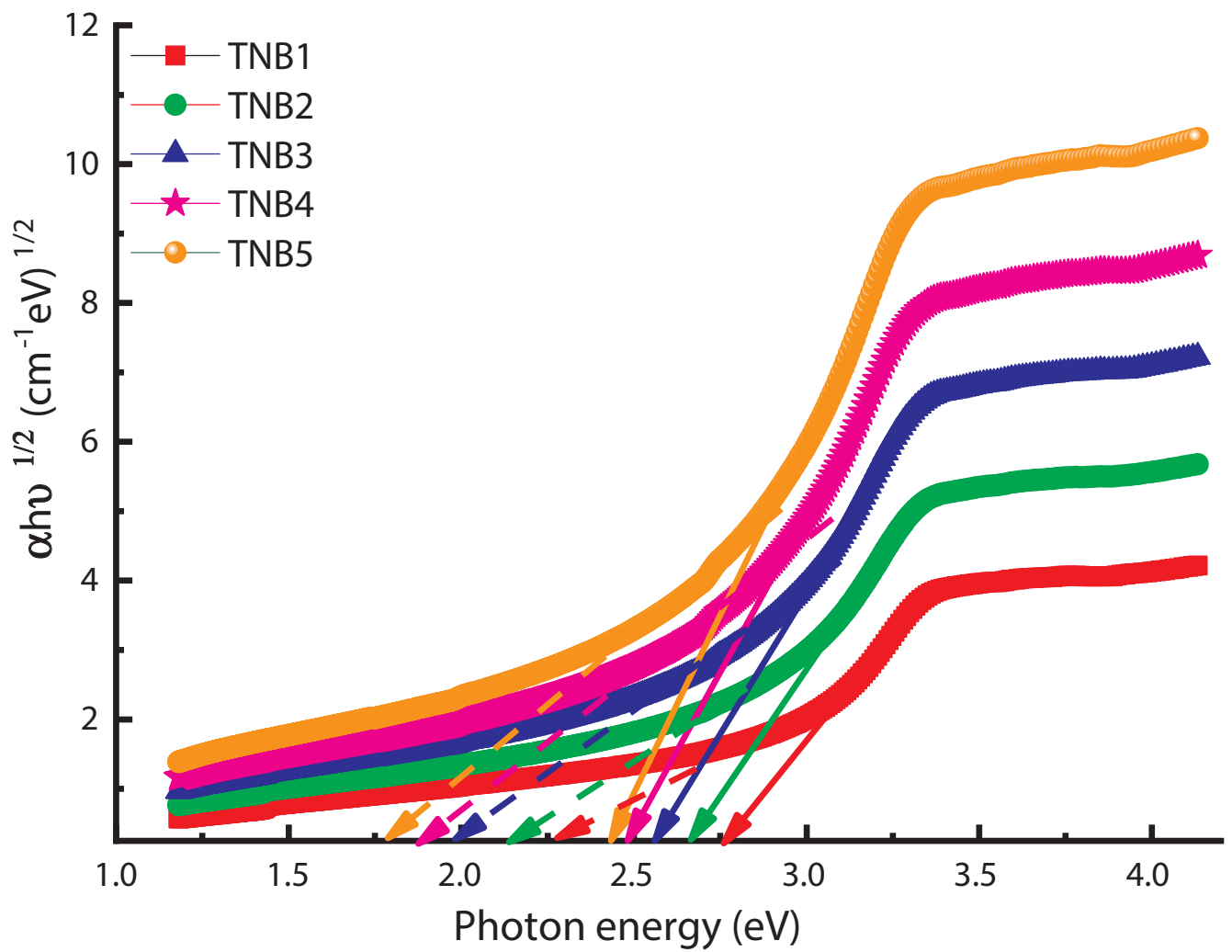

Fig. 20. $(\alpha h \nu)^{1 / 2}$ versus incident photon energy for prepared glass samples. 


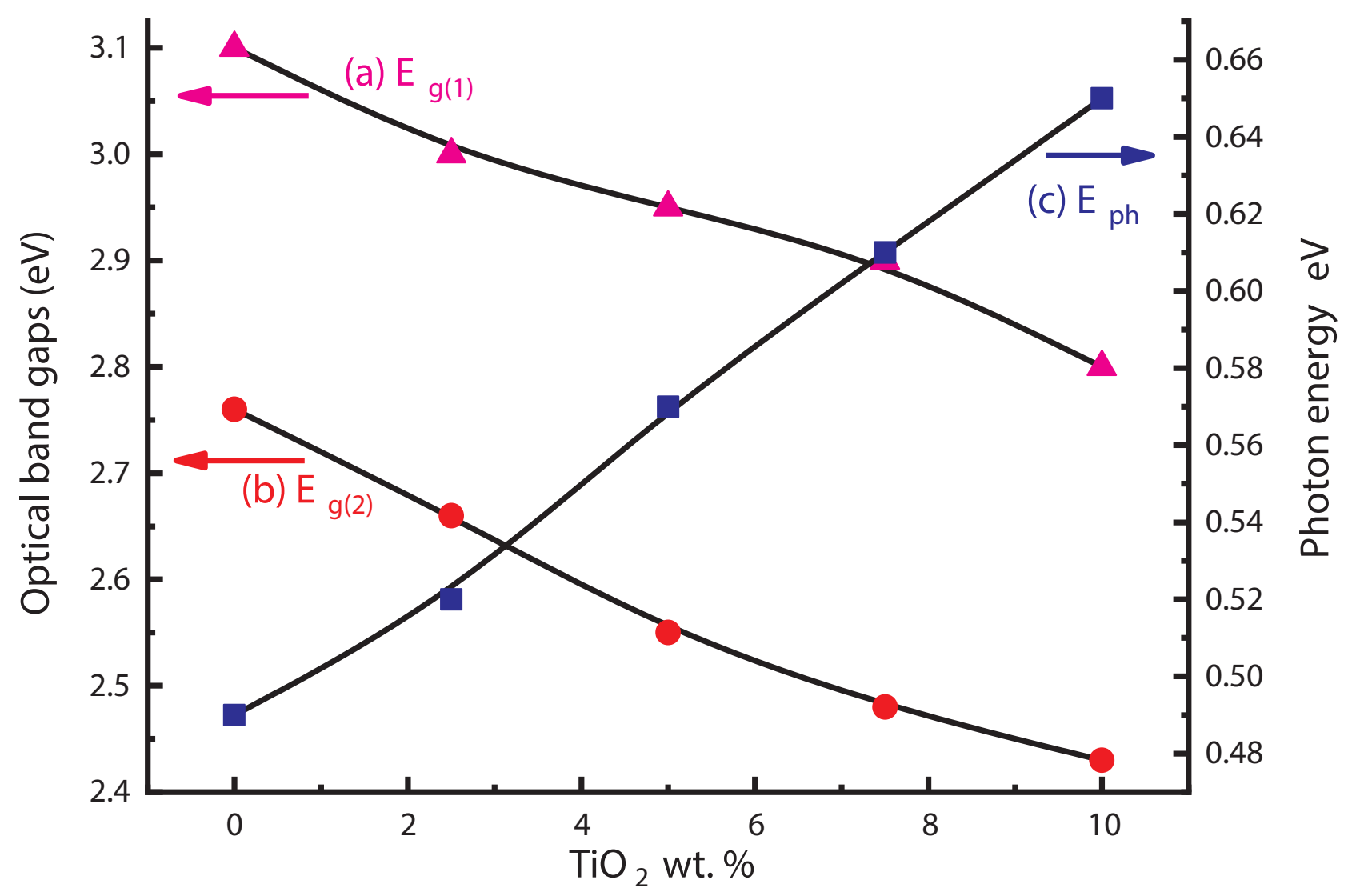

Fig. 21. (a) Direct, (b) indirect optical band gap and (c) phonon energy for prepared glass samples.

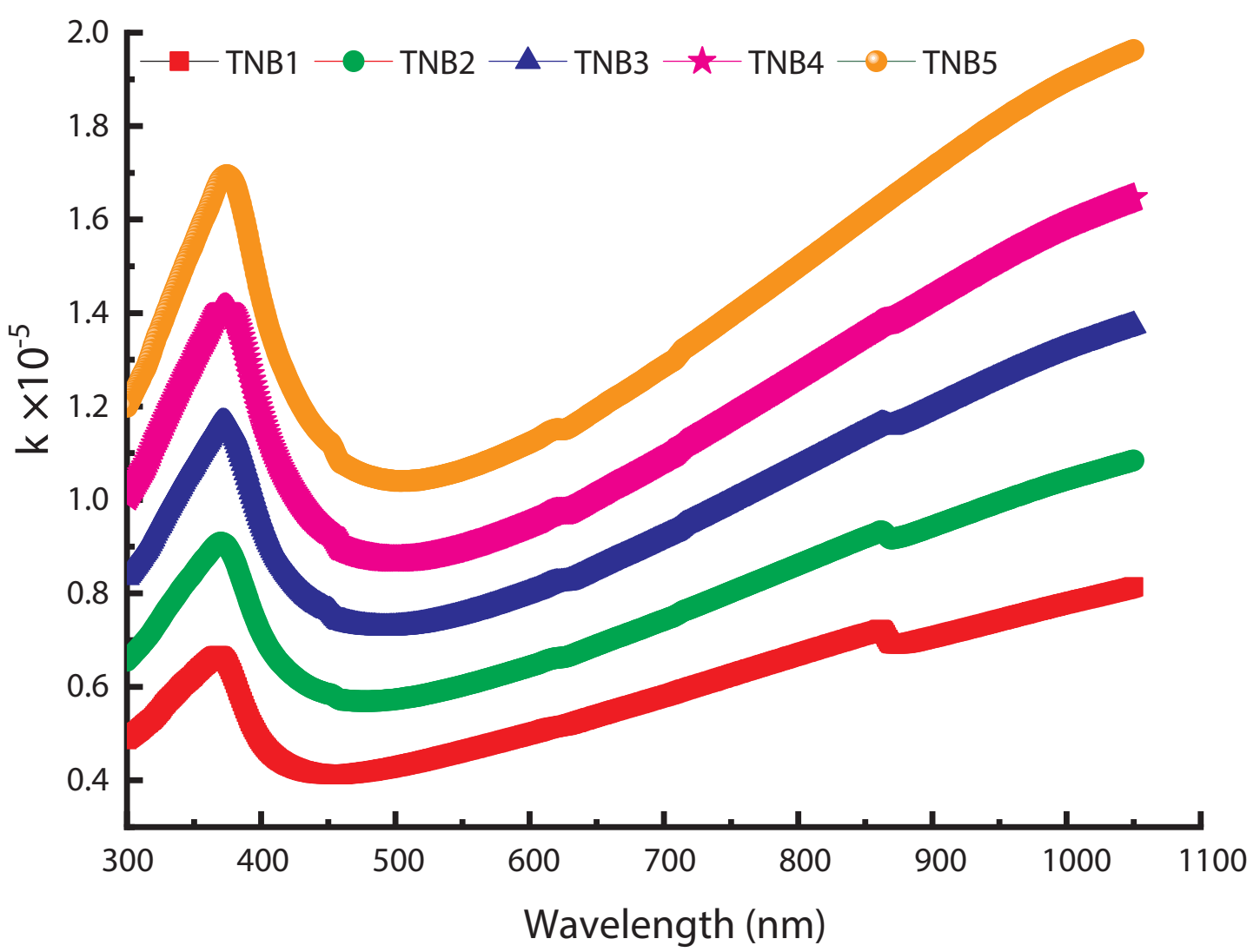

Fig. 22. Absorption index as a function of wavelength for prepared glass samples. 


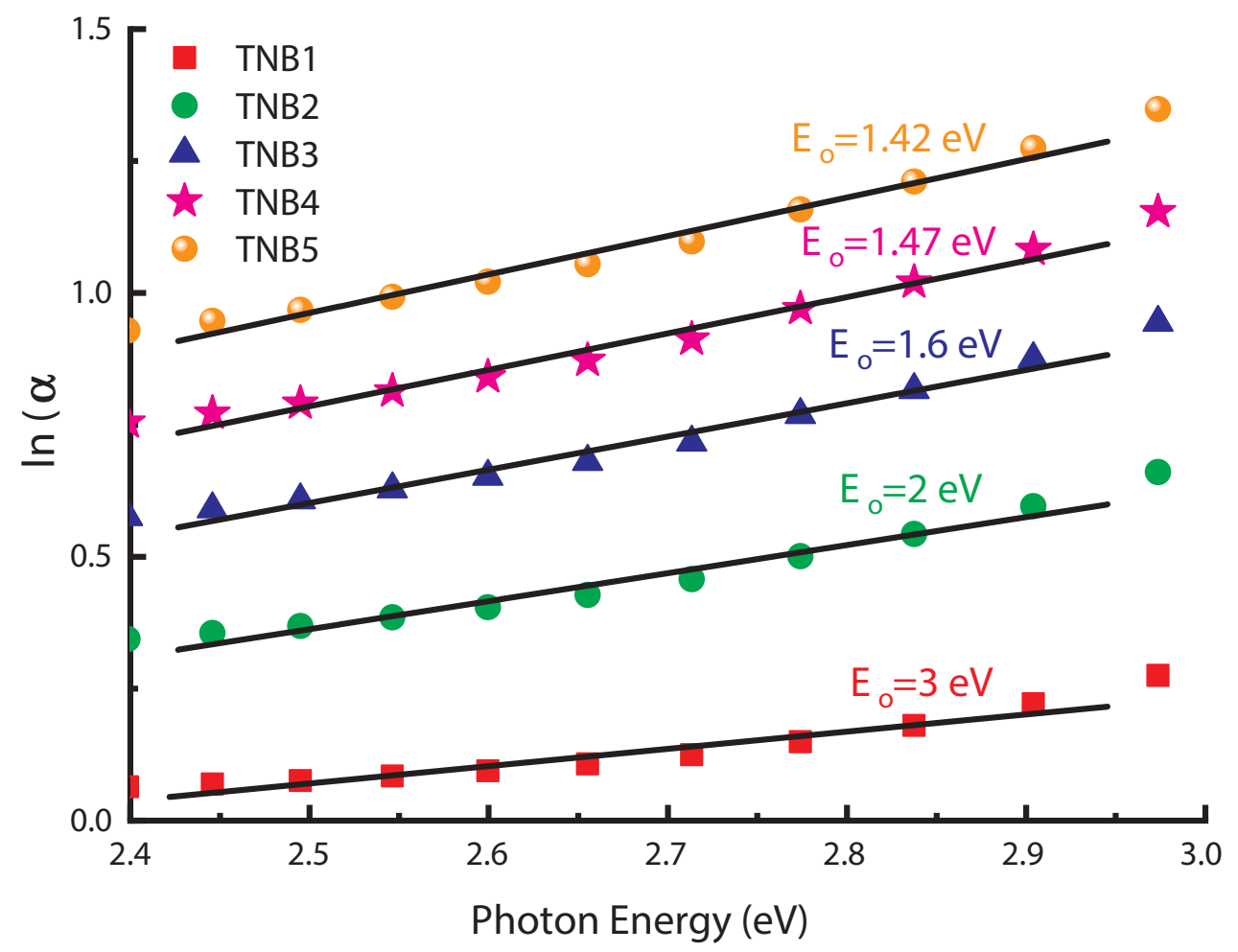

Fig. 23. $\ln (\alpha)$ versus incident photon energy for prepared glass samples.

Table 6

Chemical composition, density $(\rho)\left(\mathrm{g} / \mathrm{cm}^{3}\right)$, molecular weight $(\mathrm{M})\left(\mathrm{cm}^{3} / \mathrm{mol}\right)$, molar volume $\left(\mathrm{V}_{\mathrm{m}}\right)(\mathrm{g} / \mathrm{mol})$, packing density $\left(\mathrm{V}_{\mathrm{t}}\right)\left(\mathrm{cm}^{3} / \mathrm{mol}\right)$ and dissociation energy per unit volume $\left(\mathrm{G}_{\mathrm{t}}\right)\left(\mathrm{kJ} / \mathrm{cm}^{3}\right)$.

\begin{tabular}{llllllllll}
\hline Code & $\mathrm{TiO}_{2}$ & $\mathrm{Na}_{2} \mathrm{O}$ & $\mathrm{Bi}_{2} \mathrm{O}_{3}$ & $\mathrm{~B}_{2} \mathrm{O}_{3}$ & $\rho$ & $\mathrm{M}$ & $\mathrm{V}_{\mathrm{m}}$ & $\mathrm{V}_{\mathrm{t}}$ & $\mathrm{G}_{\mathrm{t}}$ \\
\hline $\mathrm{TNB} 1$ & 0.0 & 15 & 35 & 50.0 & 4.0251 & 207.19 & 51.47 & 0.41 & 13.69 \\
$\mathrm{TNB} 2$ & 2.5 & 15 & 35 & 47.5 & 4.0951 & 207.45 & 50.66 & 0.42 & 13.81 \\
$\mathrm{TNB} 3$ & 0.5 & 15 & 35 & 45.0 & 4.2521 & 207.70 & 48.85 & 0.43 & 13.92 \\
$\mathrm{TNB} 4$ & 7.5 & 15 & 35 & 42.5 & 4.4957 & 207.96 & 46.26 & 0.45 & 14.03 \\
TNB5 & 10 & 15 & 35 & 40.0 & 4.7951 & 208.22 & 43.42 & 0.47 & 14.14 \\
\hline
\end{tabular}

Table 7

Young's (Y) (GPa), bulk (k) (GPa), shear (G) (GPa), longitudinal (L) (GPa) modulus, and Poisson's ratio $(\sigma)$ values using Makishima and Mackenzie. Molar oxygen volume (MOV) $\left(\mathrm{cm}^{3} / \mathrm{mol}\right)$, oxygen packing density (OPD) (mol/L), number of bonds per unit volume $\left(\mathrm{n}_{\mathrm{b}} \times 10^{23}\right)\left(\mathrm{cm}^{-3}\right)$ and average cross-link density (ACD).

\begin{tabular}{llllllllll}
\hline Code & $\mathrm{Y}$ & $\mathrm{K}$ & $\mathrm{G}$ & $\mathrm{L}$ & $\sigma$ & $\mathrm{MOV}$ & $\mathrm{OPD}$ & $\mathrm{n}_{\mathrm{b}}$ & $\mathrm{ACD}$ \\
\hline TNB1 & 47.19 & 23.26 & 21.78 & 52.31 & 0.16 & 19.06 & 52.45 & 5.25 & 4.50 \\
TNB2 & 47.98 & 23.86 & 22.09 & 53.31 & 0.17 & 18.94 & 52.81 & 5.42 & 4.56 \\
TNB3 & 49.79 & 25.49 & 22.72 & 55.78 & 0.18 & 18.43 & 54.25 & 5.71 & 4.62 \\
TNB4 & 52.60 & 28.22 & 23.68 & 59.79 & 0.19 & 17.62 & 56.75 & 6.13 & 4.68 \\
TNB5 & 56.05 & \multirow{2}{*}{31.80} & 24.86 & 64.94 & 0.21 & 16.70 & 59.88 & 6.63 & 4.74 \\
\hline
\end{tabular}

are plotted in Figs. 11 and 12, respectively. The highest RPE value, $84.22 \%$, for the TNB5 sample occurs at $80 \mathrm{keV}$ for $10 \mathrm{wt}-\% \mathrm{TiO}_{2}$ concentration, which has a RPE value $110 \%$ higher than the TNB1 sample. The lowest RPE value, $10.95 \%$, for the TNB5 sample occurs at $1408 \mathrm{keV}$ for $10 \mathrm{wt} \% \mathrm{TiO}_{2}$ concentration, which has a RPE value $128 \%$ higher than the TNB1 sample (Fig. 11). The higher RPE results for the TNB5 sample are due to increased $\mathrm{TiO}_{2}$ content. The TF of TNB5 (10 wt $\%$ ), which is the opposite of RPE, is the lowest among all the samples at an $\mathrm{E}$ of $81 \mathrm{keV}$ energy (Fig. 12). The TF increases in the 81-1408 keV energy region and decreases at $128.8 \mathrm{keV}$ due to the $\mathrm{K}$ absorption edge of $\mathrm{Bi}$. Due to the fact that it has the highest $\mathrm{TiO}_{2}$ concentration, the TNB5 (10 wt \%) sample is the best attenuator among all the samples, particularly in the low-energy region.

The thicknesses of $\mathrm{Pb}$ required to obtain the same shielding effect against gamma radiation $\left(\mathrm{d}_{\mathrm{Pb}}\right)$ are plotted in Fig. 13 and Table 4. The $\mathrm{d}_{\mathrm{Pb}}$ values increase as TiO2 increases from 0 to $10 \mathrm{wt} \%$ and decrease as $\mathrm{E}$ increases. The buildup factor (BF) results for the TNB1, TNB2, TNB3, TNB4, and TNB5 samples are shown in Fig. 14 and Table 5. The BF results decrease as TiO2 increases from 0 to $10 \mathrm{wt} \%$. The theoretical $\Sigma_{\mathrm{R}}$ results for the TNB1, TNB2, TNB3, TNB4, and TNB5 samples are shown in Fig. 15. The $\Sigma_{\mathrm{R}}$ values increase in the following order: TNB1 (0 wt \%) $\left(0.1326 \mathrm{~cm}^{-1}\right)<\operatorname{TNB} 2(2.5 \mathrm{wt} \%)\left(0.1331 \mathrm{~cm}^{-1}\right)<\operatorname{TNB} 3(5 \mathrm{wt} \%)$ $\left(0.1364 \mathrm{~cm}^{-1}\right)<\operatorname{TNB} 4\left(7.5 \mathrm{wt}^{-1}\right)\left(0.1422 \mathrm{~cm}^{-1}\right)<\operatorname{TNB} 5$ (10 wt \%) $\left(0.1497 \mathrm{~cm}^{-1}\right)$. The fact that the TNB5 (10 wt \%) sample has the highest $\Sigma_{\mathrm{R}}$ may be due to the large elemental composition of high-Z.

\subsection{Optical properties}

The absorbance of the samples was measured in the wavelength range of (190-1100) nm. It is illustrated that there is a clear absorbance peak for all the samples in the near-ultraviolet (UVA) area centred at $370 \mathrm{~nm}(3.35 \mathrm{eV})$. It is well known that ultraviolet light is emitted from the sun in three types: long UVA light (the largest wavelength and low energy), UVB medium-light, and short UVC light (a shorter wavelength and greater energy) [31] (Fig. 16). Both UVA and UVB light can destroy vitamin A in human skin [32]. UVC light is the most dangerous as it can kill living cells, but it does not harm life on Earth because it is absorbed in the ozone layer and the outer layer of the atmosphere. Only ultraviolet light with medium and long wavelengths penetrates the ozone layer and atmosphere: excessive exposure to such light leads to harmful effects [33], such as burns, skin cancer, and eye diseases. It was previously thought that UVA is less harmful than UVB, but this is not correct. It has been proved that UVB can contribute to skin cancer, which damages DNA. It can generate free radicals such as reactive oxygen species [34]. In our case, the absorbance of $\mathrm{xTiO}_{2}$ $15 \mathrm{Na}_{2} \mathrm{O}-30 \mathrm{Bi}_{2} \mathrm{O}_{3}-(50-\mathrm{x}) \mathrm{B}_{2} \mathrm{O}_{3}$ glasses (where $\mathrm{x}=0,2.5,5,7.5$ and 


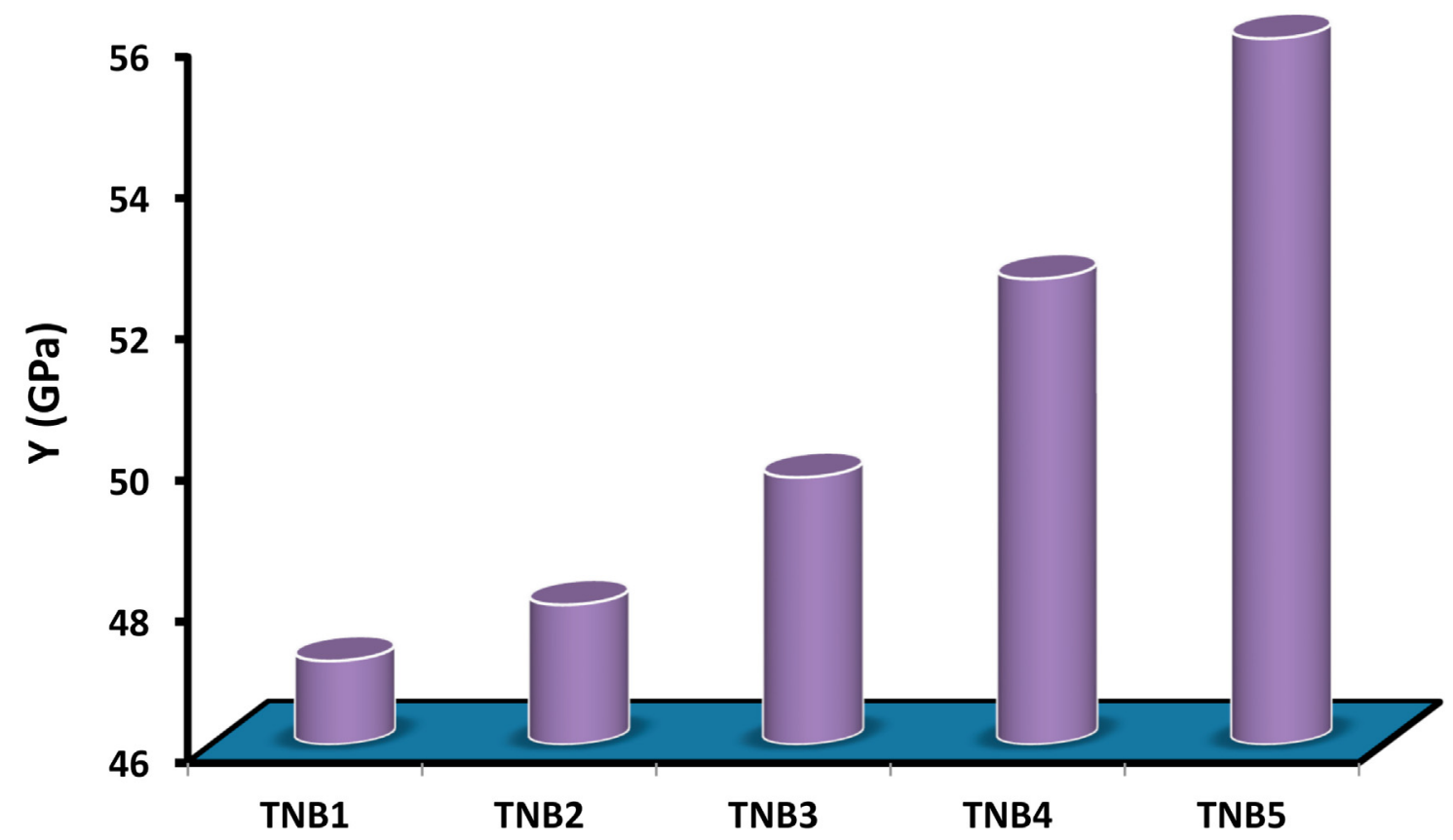

Fig. 24. Young's modulus (Y) values using Makishima and Mackenzie model for glass samples.

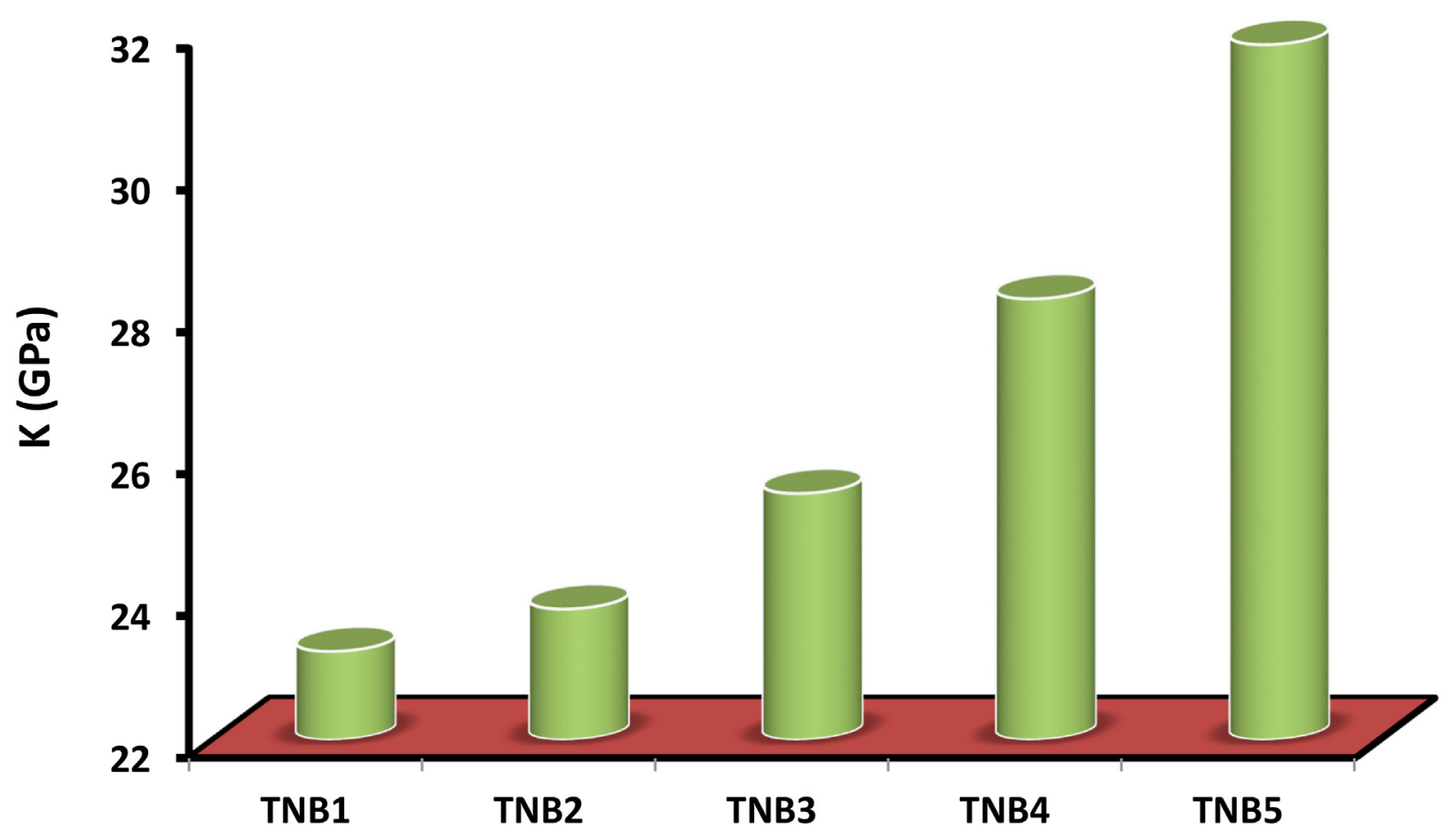

Fig. 25. Bulk modulus (Y) values using Makishima and Mackenzie model for glass samples.

$10 \mathrm{wt} \%$ ) increases as the $\mathrm{TiO} 2$ content increases from 0 to $10 \mathrm{wt} \%$. Therefore, the present samples can be used to protect humans from UVA light. The optical absorption spectra of undoped soda lime borosilicate glass in a wavelength range of $300-1100 \mathrm{~nm}$ have been studied, along with the optical absorption spectra of samples doped with different levels of $\mathrm{Bi}_{2} \mathrm{O}_{3}$ [35]. It can be observed that the absorption edge slightly shifts to the longer wavelength as the $\mathrm{Bi}_{2} \mathrm{O}_{3}$ concentration increases. On the other hand, in case of $\mathrm{PbO}$, the result is similar to that from $\mathrm{Bi}_{2} \mathrm{O}_{3}$. It can be observed that the absorbance increases as the $\mathrm{Bi}_{2} \mathrm{O}_{3}$ or $\mathrm{PbO}$ concentration increases. Therefore, the $\mathrm{xTiO}_{2}-$ $15 \mathrm{Na}_{2} \mathrm{O}-30 \mathrm{Bi}_{2} \mathrm{O}_{3}-(50-\mathrm{x}) \mathrm{B}_{2} \mathrm{O}_{3}$ glass samples (where $\mathrm{x}=0,2.5,5,7.5$ and $10 \mathrm{wt} \%$ ) can be used for protection from UVA light.
The absorption coefficient $(\alpha)$ can be calculated using the following equation [36]:

$\alpha=2.303(A / t)$

where $\mathrm{t}$ is film thickness.

Fig. 17 shows the dependence of the absorption coefficient $(\alpha)$ on the intendant photon energy $(h \nu)$ for the glass samples. It is observed that with increasing $\mathrm{TiO}_{2}$ content, the value of $\alpha$ increases. Moreover, the edges shift towards lower energy regions. It is well known that the value of $\alpha$ depends on $h \nu$ according to the following equation [37]:

$(\alpha h v)^{m}=A\left(h v-E_{g}\right)$ 


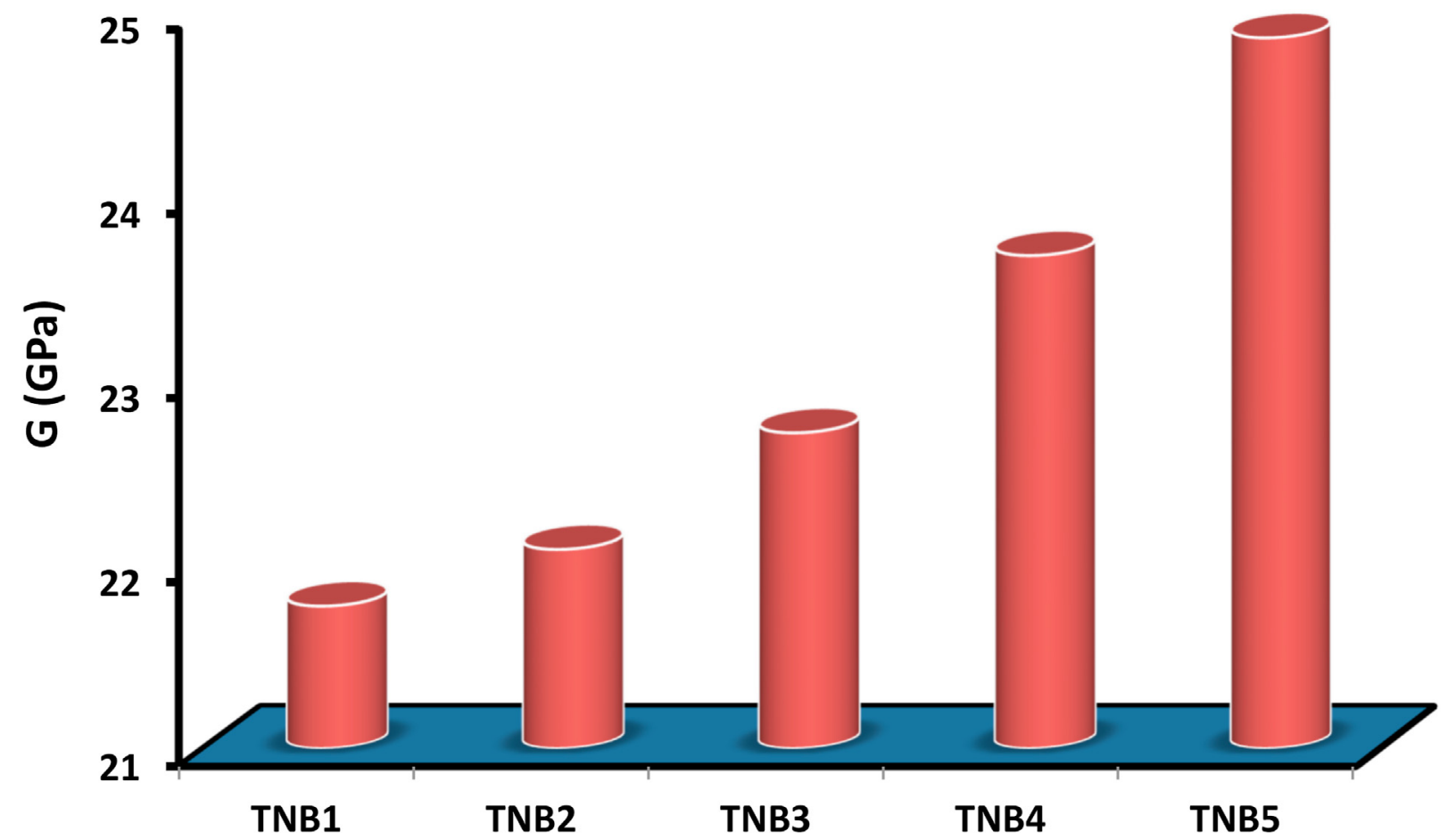

Fig. 26. Shear modulus (Y) values using Makishima and Mackenzie model for glass samples.

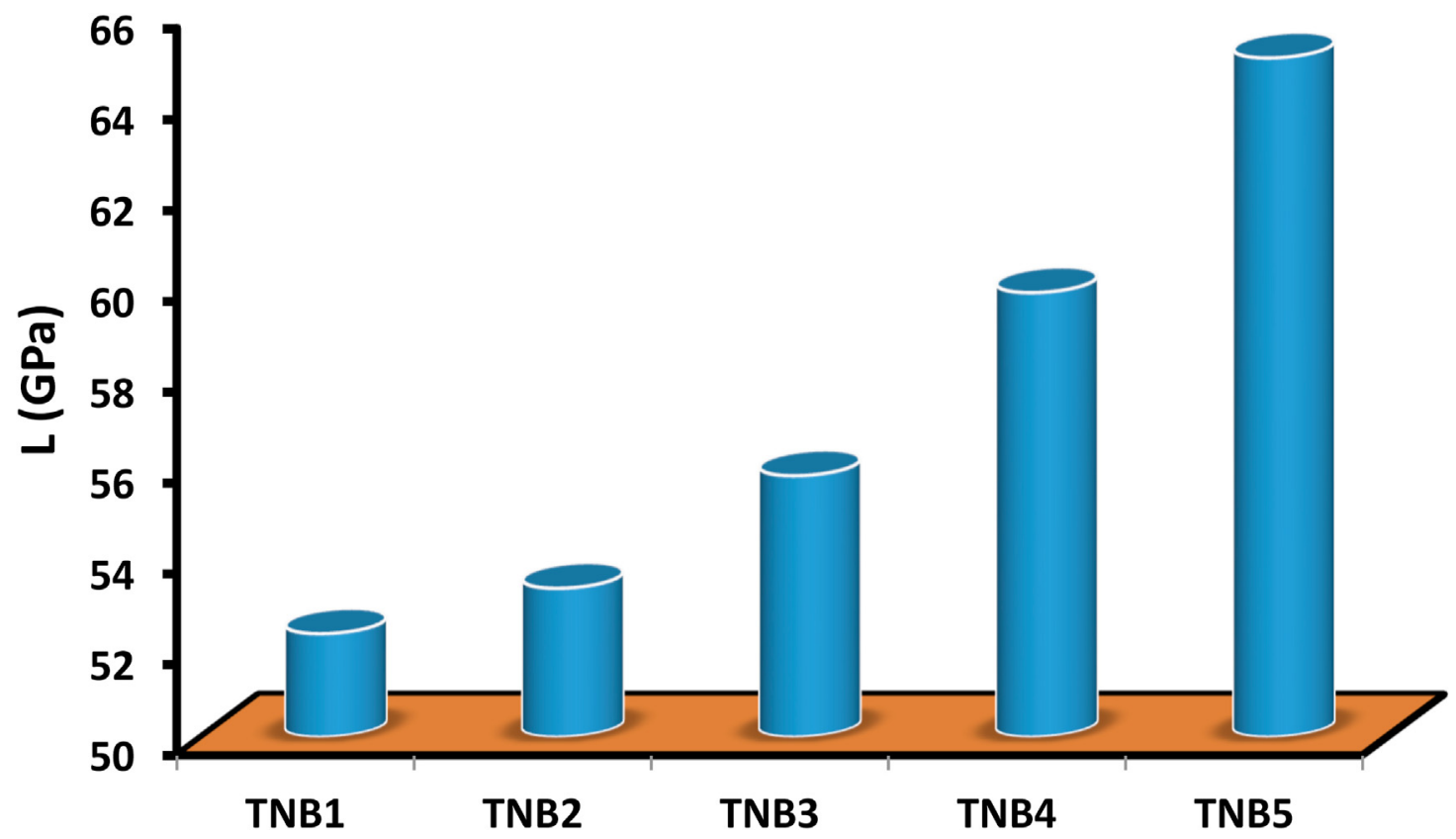

Fig. 27. Longitudinal modulus (L) values using Makishima and Mackenzie model for glass samples.

where $\mathrm{Eg}$ is the optical band gap, and $\mathrm{m}$ is the power indicated in the transition process. If $\mathrm{m}=2$, it is direct allowed transition. If $\mathrm{m}=1 / 2$, it is indirect allowed transition. It is known that there are two major optical transition probabilities; (i) optical direct and (ii) indirect transition. For the probability of direct transition $(\mathrm{m}=2)$, Fig. 18 shows the dependence of $(\alpha h \nu)^{2}$ on the incident photon energy of the glass samples. (ii) For the probability of indirect transition $(\mathrm{m}=1 / 2)$. Therefore, eq. (24) takes the following form [37]:

$(\alpha h \nu)^{1 / 2}=A\left(h \nu-E_{g} \pm E_{p h}\right)$

where $\mathrm{E}_{\mathrm{ph}}$ is the phonon energy.

Fig. 19 illustrates the relation of $(\alpha h \nu)^{1 / 2}$ versus photon energy (hv) plots for the studied glass samples. The intercept of the straight line with the photon energy axis at $(\alpha h \nu)^{2}=0$ and $(\alpha h \nu)^{1 / 2}=0$, respectively, gives the optical band gap, $E_{g 1 \text { (indirect) }}$, and $E_{\text {g1(direct). }}$ As is well known, indirect transitions are valid for amorphous materials. Fig. 20 shows the dependence of the two types of optical band gap and the phonon energy for the TNB1, TNB2, TNB3, TNB4, and TNB5 samples.

The values of the two types of optical band gap decrease as the $\mathrm{TiO}_{2}$ content increases. This behavior can be understood in terms of the structural changes taking place in the glass systems [38]. This decrease is seen because of the development of new Bi-O-B bonds. These new bonds are formed because of the incitement of the electrostatic field of the firmly polarizing $\mathrm{Bi}^{3+}$ particles. The bond force stretching constant 
will decrease, since the bond force stretching constant of $\mathrm{Bi}-\mathrm{O}$ is lower than that of the $\mathrm{B}-\mathrm{O}$ bond. Therefore, the $\mathrm{Bi}-\mathrm{O}$ bond length increases, thus expanding the glass and replacing $\mathrm{B}-\mathrm{O}$ linkages with $\mathrm{Bi}-\mathrm{O}$ and Ti-O linkages, which are weaker. Furthermore, accessible oxygen around the bismuth cations will increase, thus diminishing the estimations of $E_{g}$ Ref. [38].

The extinction coefficient $(\mathrm{k})$ can be calculated as follows [39]:

$k=\frac{\alpha \lambda}{4 \pi}$

The dependences of $\mathrm{k}$ at different wavelengths for the TNB1, TNB2, TNB3, TNB4, and TNB5 samples are shown in Fig. 21. In Fig. 21, it is pretty obvious that $\mathrm{k}$ increases as the $\mathrm{TiO}_{2}$ content increases. The absorption-coefficient close to the absorption-edge obeys the empirical Urbach rule at a particular temperature can be defined with next formula [40]:

$\alpha=\alpha_{o} e^{\frac{h \nu}{E_{0}}}$

In this formula, $\alpha_{o}$ is the constant and $E_{o}$ is the width of localized states. The relationship between $\ln (\alpha)$ vs photon energy (hv) for the glass samples is given in Fig. 22. $\mathrm{E}_{\mathrm{o}}$ values are tabulated in Fig. 23: these reflect increased behavior as the $\mathrm{TiO}_{2}$ content increases. As illustrated in this figure, the electronic transition between localized states is valid for the TNB1, TNB2, TNB3, TNB4, and TNB5 samples.

\subsection{Mechanical properties}

The computed mechanical parameters of the investigated TNB1, TNB2, TNB3, TNB4, and TNB5 samples are advantageous for designing of radiation shielding materials [41-44]. The $M, V_{m}, V_{t}$, and $G_{t}(Y, K, G$, $\mathrm{L}$, and $\sigma$ ) moduli and the MOV, OPD, $\mathrm{n}_{\mathrm{b}}$, and ACD values are evaluated and listed in Tables 6 and 7. As listed in these tables, the M, Vm, Vt, Gt $\mathrm{OPD}, \mathrm{n}_{\mathrm{b}}, \sigma$, and $\mathrm{ACD}$ values increase as the $\mathrm{TiO}_{2}$ concentration increases from 0 to $10 \mathrm{wt} \%$. The relationship between the elastic moduli (Y, K, G, and $\mathrm{L}$ ) and the $\mathrm{TiO}_{2}$ concentration are shown in Figs. 24-27, respectively. The $\mathrm{Y}, \mathrm{K}, \mathrm{G}$, and $\mathrm{L}$ results increase as the $\mathrm{TiO}_{2}$ concentration increases. This may be due to the fact that the elastic moduli depend on density, which means the enhancement of the rigidity of the glass samples.

\section{Conclusion}

In today's world, the number of new and promising technological developments is rapidly increasing, thanks to multidisciplinary studies. This situation provides a remarkable possibility for advanced investigations in terms of multidisciplinary challenges on material science [62-66]. Among the multidisciplinary fields, radiation studies and shielding materials are significant research areas that can be performed with co-operation of different sub-fields such as nuclear physics, material sciences and chemistry. Eventually, the needs for novel and ecofriendly shielding materials have emerged even stronger in recent years. For this reason, studies on alternative shielding materials such as glasses, alloys, composites continue with very high motivation. This situation has encouraged us to fabricate a series of $\mathrm{TiO}_{2}$ rich glasses in terms of their availability to use in nuclear radiation areas. Considering the essential needs of ideal shields, we aimed to perform a large experimental characterization on different type of $\mathrm{TiO}_{2}$, reinforced glasses in terms of their optical, nuclear radiation shielding and mechanical properties. The effect of different $\mathrm{TiO}_{2}$ concentrations on the radiation shielding, optical, and mechanical properties of $\mathrm{xTiO}_{2^{-}}$ $15 \mathrm{Na}_{2} \mathrm{O}-30 \mathrm{Bi}_{2} \mathrm{O}_{3}-(50-\mathrm{x}) \mathrm{B}_{2} \mathrm{O}_{3}$ glass samples (where $\mathrm{x}=0$, 2.5, 5, 7.5 and $10 \mathrm{wt} \%$ ) were illustrated. Moreover, attenuation performance of synthesized glasses against nuclear radiation was measured at 14 energies within the range of 81-1408 keV. Some important properties, such as linear attenuation coefficients, mass attenuation coefficients, half value layer thicknesses, radiation protection efficiency, transmission factors and effective mass removal cross section values were determined. The LAC experimental results were measured using a HPGe detector. Simulated and theoretical MAC values were obtained using the FLUKA code and the XCOM database. Good agreement was observed between the experimental, simulated, and theoretical results. The TNB 5 sample $\left(10 \mathrm{TiO}_{2}\right.$ wt. \%) generally had the lowest HVL, TVL, MFP, BF, and TF values and the highest LAC, MAC, $\mathrm{d}_{\mathrm{Pb}}$, RPE, and $\Sigma_{\mathrm{R}}$ values. This means that the TNB 5 sample $\left(10 \mathrm{TiO}_{2}\right.$ wt. \%) offers superior shielding against gamma and neutron radiation compared to the other samples. The results showed that radiation shielding properties increase according to the doping ratio. Both the direct and indirect band gaps decrease as the $\mathrm{TiO}_{2}$ content increases, which could be due to the development of new $\mathrm{Bi}-\mathrm{O}-\mathrm{B}$ bonds. Our glass samples enhance absorbance as $\mathrm{TiO}_{2}$ concentration increases, evidence that the developed samples can protect humans from UV light. As a result of this study, it can be concluded that continuous researches are needed in terms of glass sciences and material development studies. The effect of reinforcement was clear. However, different types of comprehensive investigations with different additive amounts can be considered as a continuous study of our project on eco-friendly novel shields.

\section{Declaration of competing interest}

The authors declare that they have no known competing financial interests or personal relationships that could have appeared to influence the work reported in this paper.

\section{References}

[1] P. Kaur, D. Singh, T. Singh, Heavy metal oxide glasses as gamma rays shielding material, Nucl. Eng. Des. 307 (2016) 364-376, https://doi.org/10.1016/j. nucengdes.2016.07.029.

[2] W. Poltabtim, E. Wimolmala, K. Saenboonruang, Properties of lead-free gamma-ray shielding materials from metal oxide/EPDM rubber composites, Radiat. Phys. Chem. 153 (2018) 1-9, https://doi.org/10.1016/j.radphyschem.2018.08.036.

[3] Y. Cai, H. Hu, Z. Pan, W. Sun, M. Yan, Metaheuristic optimization in shielding design for neutrons and gamma rays reducing dose equivalent as much as possible, Ann. Nucl. Energy 120 (2018) 27-34, https://doi.org/10.1016/j.anucene.2018.05. 038 .

[4] Y. Cai, H. Hu, S. Lu, Q. Jia, Optimization of radiation shielding material aiming at compactness, lightweight, and low activation for a vehicle-mounted acceleratordriven D-T neutron source, Appl. Radiat. Isot. 135 (2018) 147-154, https://doi.org/ 10.1016/j.apradiso.2018.01.021.

[5] M.S. El-Genk, Deployment history and design considerations for space reactor power systems, Acta Astronaut. 64 (2009) 833-849, https://doi.org/10.1016/j. actaastro.2008.12.016.

[6] Handbook of Nuclear Engineering, first ed., Springer, Boston, MA, USA, 2010.

[7] F. Özkalaycı, M.R. Kaçal, O. Agar, H. Polat, A. Sharma, F. Akman, Lead(II) chloride effects on nuclear shielding capabilities of polymer composites, J. Phys. Chem. Solid. 145 (2020) 109543, https://doi.org/10.1016/j.jpcs.2020.109543.

[8] E. Şakar, Determination of photon-shielding features and build-up factors of nickel-silver alloys, Radiat. Phys. Chem. 172 (2020) 108778, https://doi.org/10.1016/ j.radphyschem.2020.108778.

[9] C.-M. Lee, Y.H. Lee, K.J. Lee, Cracking effect on gamma-ray shielding performance in concrete structure, Prog. Nucl. Energy 49 (2007) 303-312.

[10] H.A. Saudi, W.M. Abd-Allah, K.S. Shaaban, Investigation of gamma and neutron shielding parameters for borosilicate glasses doped europium oxide for the immobilization of radioactive waste, J. Mater. Sci. Mater. Electron. 31 (2020) 6963-6976, https://doi.org/10.1007/s10854-020-03261-6.

[11] N. Gupta, A. Kaur, A. Khanna, F. Gonzàlez, C. Pesquera, R. Iordanova, B. Chen, Structure-property correlations in TiO2-Bi2O3-B2O3-TeO2 glasses, J. Non-Cryst. Solids 470 (2017) 168-177, https://doi.org/10.1016/j.jnoncrysol.2017.05.021.

[12] Y.S. Rammah, M.I. Sayyed, A.S. Abohaswa, H.O. Tekin, FTIR, electronic polarizability and shielding parameters of $\mathrm{B} 2 \mathrm{O} 3$ glasses doped with SnO2, Appl. Phys. A 124 (2018) 650, https://doi.org/10.1007/s00339-018-2069-4.

[13] M.I. Sayyed, I.A. El-Mesady, A.S. Abouhaswa, A. Askin, Y.S. Rammah, Comprehensive study on the structural, optical, physical and gamma photon shielding features of B2O3-Bi2O3-PbO-TiO2 glasses using WinXCOM and Geant4 code, J. Mol. Struct. 1197 (2019) 656-665, https://doi.org/10.1016/j.molstruc. 2019.07.100.

[14] H.O. Tekin, L.R.P. Kassab, O. Kilicoglu, E.S. Magalhães, S.A.M. Issa, G.R. da Silva Mattos, Newly developed tellurium oxide glasses for nuclear shielding applications: an extended investigation, J. Non-Cryst. Solids (2019) 119763, https://doi.org/10. 1016/j.jnoncrysol.2019.119763.

[15] S.A.M. Issa, A.M.A. Mostafa, T.A. Hanafy, M. Dong, X. Xue, Comparison study of 
photon attenuation characteristics of Poly vinyl alcohol (PVA) doped with $\mathrm{Pb}(\mathrm{NO} 3)$ 2 by MCNP5 code, XCOM and experimental results, Prog. Nucl. Energy 111 (2019) 15-23, https://doi.org/10.1016/j.pnucene.2018.10.018.

[16] S.A.M. Issa, M.I. Sayyed, M. Kurudirek, Study of gamma radiation shielding properties of ZnO-TeO2 glasses, Bull. Mater. Sci. 40 (2017) 841-857, https://doi.org/ 10.1007/s12034-017-1425-x.

[17] S.A.M. Issa, T.A. Hamdalla, A.A.A. Darwish, Effect of $\mathrm{ErCl} 3$ in gamma and neutron parameters for different concentration of ErCl3-SiO2 (EDFA) for the signal protection from nuclear radiation, J. Alloys Compd. 698 (2017) 234-240, https://doi. org/10.1016/j.jallcom.2016.12.176.

[18] M.Y.A. Mostafa, M. Vasyanovich, M. Zhukovsky, A primary standard source of radon-222 based on the HPGe detector, Appl. Radiat. Isot. 120 (2017) 101-105, https://doi.org/10.1016/j.apradiso.2016.12.012.

[19] Y.A.M. Mostafa, M. Vasyanovich, M. Zhukovsky, N. Zaitceva, Calibration system for radon EEC measurements, Radiat. Protect. Dosim. 164 (2015) 587-590, https://doi. org/10.1093/RPD/NCV316.

[20] M.J. Berger, J.H. Hubbell, S.M. Seltzer, J. Chang, J.S. Coursey, R. Sukumar, D.S. Zucker, K. Olsen, XCOM: Photon Cross Section Database, National Institute of Standards and Technology, Gaithersburg, MD, 2010 [Online] Available http:// physics.nist.gov/xcom, version 1.52020, August 3.

[21] S.A.M. Issa, A.M. Ali, G. Susoy, H.O. Tekin, Y.B. Saddeek, R. Elsaman, H.H. Somaily, H. Algarni, Mechanical, physical and gamma ray shielding properties of xPbO-(50$\mathrm{x})$ MoO3-50V2O5 (25 $\leq \mathrm{x} \leq 45 \mathrm{~mol} \%$ ) glass system, Ceram. Int. 46 (2020) 20251-20263, https://doi.org/10.1016/j.ceramint.2020.05.107.

[22] S.A.M. Issa, H.A. Saudi, H.M.H. Zakaly, M. Rashad, A.I. Elazaka, M. Pyshkina, H.O. Tekin, Four-step investigation on B2O3-Ti2O3-Li2O-Sm2O3 glasses: synthesis, FTIR, nuclear radiation shielding and optical properties, Ceram. Int. (2020), https://doi.org/10.1016/j.ceramint.2020.07.110.

[23] A. Kumar, Gamma ray shielding properties of PbO-Li2O-B2O3 glasses, Radiat. Phys. Chem. 136 (2017) 50-53, https://doi.org/10.1016/j.radphyschem.2017.03.023.

[24] F. Ballarini, G. Battistoni, M. Brugger, M. Campanella, M. Carboni, F. Cerutti, A. Empl, A. Fassò, A. Ferrari, E. Gadioli, M.V. Garzelli, M. Lantz, A. Mairani, A. Mostacci, S. Muraro, A. Ottolenghi, V. Patera, M. Pelliccioni, L. Pinsky, J. Ranft, S. Roesler, P.R. Sala, D. Scannicchio, G. Smirnov, F. Sommerer, S. Trovati, R. Villari, V. Vlachoudis, T. Wilson, N. Zapp, The physics of the FLUKA code: recent developments, Adv. Space Res. 40 (2007) 1339-1349, https://doi.org/10.1016/j.asr 2007.05.031.

[25] M. Rashad, H.O. Tekin, H.M. Zakaly, M. Pyshkina, S.A.M. Issa, G. Susoy, Physical and nuclear shielding properties of newly synthesized magnesium oxide and zinc oxide nanoparticles, Nucl. Eng. Technol. 52 (2020) 2078-2084, https://doi.org/10. 1016/j.net.2020.02.013.

[26] H.M. Zakaly, A.S. Abouhaswa, S.A.M. Issa, M.Y.A. Mostafa, M. Pyshkina, R. ElMallawany, Optical and nuclear radiation shielding properties of zinc borate glasses doped with lanthanum oxide, J. Non-Cryst. Solids 543 (2020) 120151, https://doi. org/10.1016/j.jnoncrysol.2020.120151.

[27] M.M. Abuzaid, G. Susoy, S.A.M. Issa, W. Elshami, O. Kilicoglu, H.O. Tekin, Relationship between melting-conditions and gamma shielding performance of fluoro-sulfo-phosphate (FPS) glass systems: a comparative investigation, Ceram. Int. 46 (2020) 15255-15269, https://doi.org/10.1016/j.ceramint.2020.03.065.

[28] S.A.M. Issa, Y.B. Saddeek, M.I. Sayyed, H.O. Tekin, O. Kilicoglu, Radiation shielding features using MCNPX code and mechanical properties of the PbO Na2O B2O3CaO Al2O3SiO2 glass systems, Compos. B Eng. 167 (2019) 231-240, https://doi.org/10. 1016/j.compositesb.2018.12.029.
[29] A. Makishma, J.D. Mackenzie, Calculation of bulk modulus, shear modulus and Poisson's ratio of glass, J. Non-Cryst. Solids 17 (1975) 147-157, https://doi.org/10. 1016/0022-3093(75)90047-2.

[30] I.I. Bashter, Calculation of radiation attenuation coefficients for shielding concretes, Ann. Nucl. Energy 24 (1997) 1389-1401, https://doi.org/10.1016/S03064549(97)00003-0.

[31] M.S. Hamdy, S. AlFaifiy, A. Al-Hajry, I.S. Yahia, Disposable, visual and cost-effective PMMA sensor for UVC radiation, Sensor. Actuator. B Chem. 229 (2016) 272-275, https://doi.org/10.1016/j.snb.2016.01.132.

[32] A.V.H. Torma, B. Berne, UV irradiation and topical vitamin A modulate retinol esterification in hairless mouse epidermis, Acta Derm. Venereol. 68 (1988) 291-299.

[33] D.H. Sliney, Photoprotection of the eye - UV radiation and sunglasses, J. Photochem. Photobiol. B Biol. 64 (2001) 166-175, https://doi.org/10.1016/S10111344(01)00229-9.

[34] A.R. Svobodová, A. Galandáková, J. Šianská, D. Doležal, R. Lichnovská, J. Ulrichová, J. Vostálová, DNA damage after acute exposure of mice skin to physiological doses of UVB and UVA light, Arch. Dermatol. Res. 304 (2012) 407-412, https://doi.org/10.1007/s00403-012-1212-x.

[35] N. Srisittipokakun, J. Kaewkhao, W. Chewpraditkul, P. Limsuwan, Comparative study of optical and spectroscopic properties of lead and bismuth on borosilicate glasses, Procedia Eng. 32 (2012) 699-705, https://doi.org/10.1016/j.proeng.2012. 01.1329.

[36] J.W. Robinson, Atomic Spectroscopy, second ed., Taylor \& Francis, 1996.

[37] M. Rashad, Tuning optical properties of polyvinyl alcohol doped with different metal oxide nanoparticles, Opt. Mater. 105 (2020) 109857, https://doi.org/10. 1016/j.optmat.2020.109857.

[38] Y.B. Saddeek, K.A. Aly, A. Dahshan, I.M.E. Kashef, Optical properties of the Na2O-B2O3-Bi2O3-MoO3 glasses, J. Alloys Compd. 494 (2010) 210-213, https:// doi.org/10.1016/j.jallcom.2009.11.123.

[39] A.A. Hendi, M. Rashad, Photo-induced changes in nano-copper oxide for optoelectronic applications, Phys. B Condens. Matter 538 (2018) 185-190, https://doi. org/10.1016/j.physb.2018.03.035.

[40] A.A. El-Fadl, G.A. Mohamad, A.B.A. El-Moiz, M. Rashad, Optical constants of Zn1 xLixO films prepared by chemical bath deposition technique, Phys. B Condens Matter 366 (2005) 44-54, https://doi.org/10.1016/j.physb.2005.05.019.

[41] Yasser B. Saddeek, Shams A.M. Issa, E.E. Altunsoy Guclu, O. Kilicoglu, G. Susoy, H.O. Tekin, Alkaline phosphate glasses and synergistic impact of germanium oxide (GeO2) additive: mechanical and nuclear radiation shielding behaviors, Ceram. Int. 46 (2020) 16781-16797, https://doi.org/10.1016/j.ceramint.2020.03.254.

[42] M.A.M. Uosif, A.M.A. Mostafa, Shams A.M. Issa, H.O. Tekin, Z.A. Alrowaili, O. Kilicoglu, Structural, mechanical and radiation shielding properties of newly developed tungstenlithium borate glasses: an experimental study, J. Non-Cryst. Solids 532 (2020) 119882, https://doi.org/10.1016/j.jnoncrysol.2019.119882.

[43] Ayshah Alatawi, Abdulrhman M. Alsharari, Shams A.M. Issa, M. Rashad, A.A.A. Darwish, Yasser B. Saddeek, H.O. Tekin, Improvement of mechanical properties and radiation shielding performance of Al-Bi-BO3 glasses using yttria: an experimental investigation, Ceram. Int. 46 (2020) 3534-3542, https://doi.org/10. 1016/j.ceramint.2019.10.069.

[44] M. Gaballah, S.A.M. Issa, Y.B. Saddeek, R. Elsaman, G. Susoy, T.T. Ergüzel, T.S. AlHarbi, Mechanical and nuclear radiation shielding properties of different borotellurite glasses: A comprehensive investigation on large Bi2O3 concentration, Phys. Scripta 95 (2020) 085701, , https://doi.org/10.1088/1402-4896/ab9bde. 